\title{
¿LA HISTORIA IN-TERMINABLE?
}

\section{¿IS THE HISTORY A NEVER END TOPIC?}

Jesús Ignacio Panedas Galindo Licenciado en Ciencias Religiosas, Licenciado en Filosofía, Maestría en Filosofía. Doctor en Ciencias para la Familia. Actualmente es director del Bachillerato de la Universidad La Salle Pachuca, México. jpanedas@lasallep.edu.mx

\section{Resumen}

Esta es la primera parte de tres. Las dos primeras se plantean, aparentemente, independientes. Pareciera que entre Baudrillard y los testimonios de los sobrevivientes de los campos de exterminio no hay relación posible. Sin embargo, la historia y su fin es el hilo conductor de ambas partes. La tercera de ellas se ocupa justamente de la justificación de su relación.

Las tres partes aportarán su propia bibliografía. La conclusión final asume algunos de los pensamientos que aparecen en todo el trabajo e intenta establecer los principales puntos vertebradores del estudio.

Nos bamboleamos entre el pensamiento novedoso, posmoderno y cibernético y el testimonio, la historia y el sufrimiento del ser humano. Lo nuevo y lo de siempre. Lo que deseamos plantear es que ambos extremos no son tan extraños entre sí y que si se dieron se pueden volver a repetir. Ojalá este escrito sirva para abrir la conciencia y advertir de lo que está pendiente con los auténticos protagonistas de la historia y de lo que puede volver a ocurrir.

Palabras Clave: Fin de la historia, memoria, imagen, medios de comunicación, Apocalipsis.

\section{Abstract}

This is the first part of three. The first two arise, apparently independent. It seems that between Baudrillard and the testimonies of survivors of the camps there is no relationship possible. However, history and so is the thread from both sides. The third one deals with precisely the justification of their relationship. 
The three parties will contribute their own literature. The final conclusion assumes some of the thoughts that appear in all the work and tries to establish the main pillars of the study.

We are torn between the new thinking, postmodern, cybernetic and testimony, history and human suffering. The new and ever. What we want to make is that both ends are not strangers to each other and if they did can be repeated. Hopefully this letter will serve to open awareness and warn of what is pending with the real protagonists of history and what can happen again.

Key words: End of history, memory, image, media, Apocalypses.

\section{Introducción}

La imagen, desde la fotografía y el cine, ha sido la que ha revolucionado el mundo de los medios y la manera de relacionarnos en nuestra cultura durante los últimos cien años. Incluir el movimiento y el tiempo en las imágenes, poder llegar a multitudes para dar un mensaje, modelar o manipular las mentes a semejanza de lo que se proyecta, unificar modus vivendi mundiales, globalizar el mercado, universalizar usos y costumbres, invadir los ámbitos más individuales e íntimos mediante la televisión (y sus cientos de canales), el video y el DVD... son todas ellas consecuencias de este proceso uniformemente acelerado en el que vivimos inmersos.

A la generalización de estos medios añadamos el progresivo avance de las computadoras y medios cibernéticos. Ponen al alcance de la mano del usuario la mayor cantidad posible de información en el menor espacio necesario durante el tiempo que se requiera de la manera más rápida. Es tal el volumen que nunca una persona pudiera consultar, leer, asimilar todo ese caudal de datos.

Las repercusiones, al igual que las posibles de la manipulación genética, son todavía insospechadas. La humanidad, la ciencia y la tecnología avanzan a un ritmo vertiginoso que ya no pueden controlar ni detener. Sabemos lo que se está haciendo, intuimos lo que está por venir, pero no conocemos ni controlamos la dinámica general de todos estos procesos. Somos una hoja a la deriva de la misma tecnología que, por una parte nos hace más cómoda la vida, pero por otra, nos controla y se hace imprescindible.

No queda espacio libre en la sociedad occidental, sobre todo, y en la mundial, en donde no haga su aparición la nobleza y efectividad de los nuevos avances. La carrera es interminable y progresivamente expansiva. 
Lo que es, lo que se hace, lo que se piensa... quedan determinados ya por todas estas herramientas y artefactos.

En esta dinámica envolvente vive el hombre. Sin darse cuenta permanece pensando que lo que ve a través de las pantallas es la verdad, que lo que se escucha da certeza, que la seguridad está en las posesiones, que el pluriespacio mediático es el gran Norte que orienta nuestras vidas, que lo que se edita y publica en distintos medios nos fotografían instantáneamente los acontecimientos.

Los mas media son justamente eso: medios que interpretan la realidad para nosotros, que nos la transmiten como bombardeo diario y que se limpian las manos seguros de que la mejor opinión es la del espectador que se ha comido lo que le han dicho sin masticar ni digerir. $Y$ antes de que se den cuenta, le llega un nuevo tsunami de información para que no pueda pensar ni rebatir. Esta dinámica, analizada y discernida con una buena ración de sospecha, se revela como una situación fatal y perversa. Baudrillard es uno de los buceadores en profundidad de nuestros días sobre estas repercusiones.

En ocasiones, sus afirmaciones pueden parecer simples e, incluso, estúpidas (BAUDRILLARD, 2001) ${ }^{1}$. Pero viéndolas desde los planteamientos "objetivos" prácticos de nuestra sociedad no parecen tan exageradas. Las conclusiones pueden ser múltiples y variadas porque la "realidad" es múltiple, compleja y analógica. Es y deja de ser, es y no es, aparece y rápidamente pasa para después volver a comenzar. Lo que al menos propone nuestro autor es una explicación coherente, llevada a sus últimas consecuencias, a veces, hasta el absurdo, de los fenómenos que conocemos de nuestros días.

Coherencia como explicación global, pero basamentada en la incompatibilidad incluida dentro de la multiplicidad (BAUDRILLARD, 1993:169). El método baudrillardiano consiste justamente en constatar las últimas consecuencias, sin disfrazarlas, de los fenómenos que hoy son observables.

Todo el maremagnum de pensamiento baudrillardiano sería extensísimo y difícilmente abarcable. Es por eso, y por la cercanía con el cambio de milenio, que nos ha interesado indagar concretamente su idea de "fin". En medio de guerras, de cataclismos naturales, de preanuncios apocalípticos, de tendencias milenaristas en donde se fija o se teme el fin de nuestro mundo, Baudrillard habla de la "ilusión del fin". No puede existir un fin cuando se suprime, como nuestro tiempo mediático hace, la estructura lineal del tiempo y de la historia. Cuando se prevé que llegamos al fin resulta que volvemos a comenzar. 
El estudio que hacemos sobre la idea de fin en el autor francés, lo dividimos en tres partes. Para su denominación nos servimos de las tres partes de la película Matrix. Usamos de esta película porque su temática está directamente relacionada con la vida del hombre condicionada por las herramientas técnicas y cibernéticas. Para los sentidos del hombre todo pareciera que es normal. El desequilibrio sobreviene con el descubrimiento de que lo que se cree real no es sino una simulación generada al antojo de un gran computador central.

En la primera de ellas, Matrix, nos retrotraemos hacia los prolegómenos, no necesariamente directos, del pensamiento baudrillardiano. Dentro del

1 Sólo a Baudrillard se le ocurriría hacer esta afirmación y utilizarla como título de un libro. Cualquiera que a primera vista la lea no podrá evitar una sonrisa de extrañamiento, de cinismo o de burla ante tamaña estupidez.

pensamiento existe toda una corriente que trabaja sus ideas fuera de los cauces que a la mayoría de los profanos en filosofía parecería absurdo. Ésta es la matriz de este tipo de pensamiento.

El segundo apartado, Matrix reloaded, expone brevemente algunos de los principales puntos del pensamiento perteneciente a Baudrillard. La transformación de las masas sociales, la negación del sujeto histórico, el rechazo de la razón dialéctica y el eclipse de la forma-mercancía serían las cuatro bases sobre la que gira parte del edificio teórico de nuestro autor. Todo esto es un paso más en la radicalidad (reloaded-recargado) de los temas vistos en el primero de los apartados. Es, al mismo tiempo, la preparación para la última de las tres secciones.

El tercero, y último, de los apartados, Matrix Re (in-)volutions, se centra específicamente en la simulación del fin con todo su contexto social. Esta sección tiene una estructura especial. Los títulos de los subapartados III.1 y III.3 citan parte de las letras del extinto grupo Queen. El III.2 recuerda la figura literaria de Frankenstein con su deseo de inmortalidad. En todos ellos la necesidad histórica de la humanidad por sobrevivir a la muerte soñando con un paraíso más allá se torna en la invención de la inmortalidad ya en nuestros días, pero con otras características. 
El tiempo adquiere la forma, por mor de la celeridad, de una curvatura que rompe la linealidad histórica que estamos acostumbrados. Es por eso que hablamos de la re-volución o in- volución propia de esta nueva concepción temporal.

\section{Fin de la historia en Baudrillard}

\section{Matrix}

Ex nihilo nihil fit. Todo tiene unos referentes que lo generan y con los que se relaciona. La matriz desde la que se es conforma un conjunto de relaciones que dan identidad y soporte para crecer desde el encuentro crítico. De esta manera podemos hablar de ciertas escuelas, en sentido amplio, o corrientes de pensamiento dentro de la filosofía.

"La misión de una escuela es transmitir a la generación siguiente la tradición, la doctrina de su fundador, su primer maestro, y a tal efecto, lo más importante es mantener la doctrina inviolada... Es una tradición lo que permite o alienta las discusiones críticas entre diferentes escuelas y, lo que resulta aún más sorprendente, dentro de una y la misma escuela" (POPPER, 1999:40-41) ${ }^{2}$.

Por no irnos demasiado lejos, aunque en la dialéctica de las corrientes de filosofía pudiéramos esquematizar toda la historia de aquélla, desde la llustración se pueden definir dos grandes maneras de entender la filosofía.

Por un lado, la que se fundamenta en la firmeza de la razón, en las potencialidades del individuo, en el optimismo de la administración social. Los grandes ideales permanecen intactos y la ciencia fecunda el horizonte futuro de la humanidad. El progreso social, económico, de derechos individuales y científico mantienen al hombre en el sueño de la paz y prosperidad. Desde el cogito cartesiano se respeta, con sus reservas, el racionalismo y el idealismo de los Kant, Hegel...

En los mismos tiempos y por otro lado, existía una corriente de pensamiento paralela que negaba la necesidad del respeto por el otro,

"Los "otros" era el cuerpo en general del prójimo, la zona donde se podía, con todo el derecho que le asistía como noble, practicar cualquier clase de abuso en dicha zona. Sólo que el abuso en Sade es la negación total del "otro" como criatura moral, física, ontológica, amorosa, afectiva y social; en el "otro" aplica sus excesos y consuma sus estados de irracionalidad" (LEÓN, 2003:181-182), 
la potencia de la razón y proponía la pasión incontrolada junto con la oscuridad más profunda del ser humano. El Marqués de Sade y Baudelaire pueden ser, entre otros, dos buenos representantes (ROBERTS, 2002:165-187; PULEO, 2003:245-251).

Todos ellos desean apartarse de la ilusión de progreso y de las convenciones seguras de su época.

"Y así se oirá, en el mejor de los casos en medio del desierto y si no en el banquillo, la voz de aquellos artistas que, en un solo libro, tratan de hacer oír su diferencia, su radical rechazo a la sociedad y a sus valores alicortos: voz de Baudelaire en Las flores del mal, de Flaubert en L"Education sentimentale, de Fromentin en Dominique, voz de todos los exiliados del

2 En la primera frase se dibuja un tipo de escuela dogmática en donde sólo se transmiten conceptos y cualquier innovación es una herejía. En la segunda, se describe la tradición como generadora de crecimiento y de innovación mediante el contraste de diversas ideas. Es a ésta a la que nos referimos.

interior que no disfrutan de la grandeza épica del exilio de Hugo convertido en mala conciencia del Imperio", (VERJAT-MARTíNEZ DE MERLO, 2001:12).

Desconfían de los fundamentos que a los demás sostienen $y_{3}$ de las creencias generales, aunque implique soledad e incomprensión ${ }^{3}$.

Esta segunda parte es la que nos va a interesar. No son originales en el sentido de fundadores absolutos de una forma de ver la vida.

Son continuadores de movimientos anteriores muy antiguos. $\mathrm{Y}$, sobre todo, son referentes de grandes pensadores del siglo XIX quienes, a su vez, tienen una influencia importantísima sobre autores de nuestros días. En esta línea incluimos a Karl Marx, a Friedrich Nietzsche, posteriormente, a los estructuralistas $\mathrm{y}$, desde y con ellos a los postmodernos. Más en concreto, al autor central de esta parte de nuestro estudio: Jean Baudrillard.

Habrá un acontecimiento en el siglo XX que debilitará fuertemente las esperanzas en el primero de los modelos y dará un tono más oscuro al segundo. La Segunda Guerra Mundial, y sus consecuencias, con todas sus atrocidades, insensateces e inhumanidades pone en entredicho las capacidades de la razón humana y cuestiona los móviles reales de los individuos y de las masas. 
El idealismo es sospechoso (AMAT-PINELLA, 2002:175), la pasión irracional conduce a las masacres (KLEMPERER, 2002:381.345), el futuro es incierto, la memoria está adolorida (HENELDE ABEDASSIS, 2001:285; PEÑALVER GÓMEZ, 2000:117-138), el presente es lo que permanece como instante que tiene que disfrutarse. Si a toda esta reflexión añadimos el desarrollo de los medios, la publicidad de las vidas privadas, la cercanía de lo más lejano, la fragmentación de las noticias de todo el mundo, la duda sobre la realidad de lo que se ve en los medios, la caída de las seguridades, el imperio de la simulación... nos acercamos con paso incierto a la actualidad de lo que hoy vivimos.

Pero no tan rápido. Vayamos con pasos tranquilos analizando la influencia para el pensamiento de Baudrillard de Marx, Nietzsche (DERRIDA, 2000:26-

27) y estructuralismo. El método y la denuncia de la simulación mercantilista del primero, la teoría sobre el lenguaje del segundo y el dinamismo irrefrenable del tercero son claves de referencia explícita o implícita del autor francés. Sólo a esos mundos de estos autores nos vamos a asomar.

3 Alguien denominaría de manera general a esta corriente como "el Cogito quebrado", véase RICOEUR, 1996:XXIII-XXVIII.

\section{I.1. KARL MARX (PANEDAS, 1991:305-363)}

Fue un heredero inconformista de la tradición filosófica anterior. Bebe de Hegel toda la influencia que éste tuvo en su tiempo, en sus principios sigue su pensamiento, aunque no muy tarde, rompe con el idealismo y mantiene como útil la base de la dialéctica. La oposición, la negación se toma en cuenta como término importante de la realidad (HEGEL, 1998:15) ${ }^{4}$. El principio de identidad no necesariamente nos lleva a un conocimiento cierto de lo que las cosas son (HEGEL, 1998:8). Si es más fácil saber qué no es algo habrá que empezar a desenmascarar las verdades que, aunque aparentemente sólidas, no son tales.

Ambos extremos se necesitan para llegar a una síntesis o negación de la negación que es el devenir (werden) (MARÍAS, 1997:311-313). Éste es el auténtico conocimiento que no tiene fin, que constantemente relaciona lo que algo es y lo que no es en una unidad superior (contiene lo favorable de ambas) que a su vez se sitúa en el ser y necesita del no ser... Para Hegel existe un fin de este proceso: el espíritu absoluto ${ }^{5}$. Para Marx, siguiendo esta misma estructura, el fin de la antítesis social será el hombre total de la sociedad comunista (MARX, 1975:127). 
Mientras se llega a ella hay que descubrir, desenmascarar y suprimir ciertas estructuras que se imponen al hombre y le hacen perder su humanidad. El hombre debe tener un equilibrio y una relación con la naturaleza para cubrir sus necesidades. El medio es el trabajo. Romper este equilibrio y convertirse en un sistema simulador de bienestar a costa del hombre se lleva a cabo mediante el dinero. El capital compra el producto del trabajo, se apropia de los medios de producción y hace prevalecer el valor de uso sobre el valor de cambio. La alineación (veräusserung-entäusserung-entfremdung) es, pues, el estado propio del proletario que no puede expresarse mediante el producto de su trabajo.

4 Algo muy parecido era el pensamiento de Heráclito con su pensamiento de que todo fluye y de que la manera de progresar es la relación de los opuestos. Posteriormente otros filósofos (Aristóteles, Kant, Fichte...) tendrán en cuenta esta inquietud, quizá con la nomenclatura de "ser" y "noser" y con la inquietud de explicar los cambios o lo que clásicamente se entendía por "movimiento". Será Hegel quien la consume sistemáticamente. Véase también FLORES GARCíA, 1997:154.173.

5 Algunos autores hablan de que el estado que encarna ese espíritu absoluto y, por tanto es estadio más perfecto de evolución dialéctica dentro de la historia, es el prusiano; otros dicen que lo que realmente Hegel defendió es que el futuro absoluto estaba en América, Véase WALSH,

1997:169-182, especialmente 179-180). Ya desde Hegel aparecen dos puntos claros que nos servirán para el estudio de Baudrillard: el debilitamiento del sujeto a favor del poder estatal y la idea de un fin perfecto universal, véase HEGEL, 1999:65-66.

El sistema capitalista origina, como ya hemos mencionado, una serie de supraestructuras que mantienen la deshumanización del hombre y que desaparecerán por sí mismas cuando acabe el sistema del capital. Justicia, ética, religión, estado... son algunas de las más características.

"Y si en toda ideología, los hombres y sus relaciones aparecen invertidos como en la caja oscura, este fenómeno proviene igualmente de su proceso histórico de vida, como la inversión de los objetos al proyectarse sobre la retina proviene de su proceso de vida directamente físico... La moral, la religión, la metafísica y cualquier otra ideología y las formas de conciencia que a ellas corresponden pierden, así, la apariencia de su propia substantividad. No tienen su propia historia ni su propio desarrollo, sino que los hombres que desarrollan su producción material cambian también, al cambiar esta realidad, su pensamiento y los productos de su pensamiento. 
No es la conciencia la que determina la vida, sino la vida la que determina la conciencia" (CAMPS, 1999:576 nota 17).

La justicia y la ética de la que se habla en los tiempos de Marx es una ética clasificada por él como burguesa y, por tanto, caduca.

"El marxismo, y no sólo él, también los existencialismos y los positivismos de principios de siglo, arrasaron y barrieron los restos de una moral basada, a fin de cuentas, en la buena voluntad del individuo... Esas críticas radicales fueron provechosas y acabaron definitivamente con el individualismo metodológico -con el solipsismo en fin- de las teorías típicas de la modernidad" (CAMPS, 1996:38; CAMPS, 1999:549).

¿De qué tipo de derechos y condiciones humanas podemos hablar si los trabajadores se convierten, por dinero, en la prolongación de una herramienta?.

Respecto a la religión y los valores que ella predica son pura ensoñación, puro engaño, pura ilusión elevada a las más altas cotas para consuelo de las almas.

"En mucho de esto Marx sigue a Feuerbach. Dios es una ilusión y lo cierto es la divinización del propio hombre: "Si la esencia del hombre es el ser supremo del hombre, así también el amor del hombre por el hombre debe ser prácticamente la ley suprema. Homo homini Deus est; éste es el primer principio práctico, éste es el momento crítico de la historia del mundo" (FEUERBACH, 1975:300).

La religión es el opio del pueblo, es la perfecta adormecedora de los impulsos revolucionarios en la tierra para ganarse el cielo.

El estado y el derecho son males necesarios que desaparecerán cuando el tiempo socialista se encargue de generar, siguiendo el impulso burgués, la suficiente producción como para que la humanidad no tenga que venderse al postor más cruel. El socialismo (Rohe Kommunismus), heredero de los socialistas utópicos, empero con sus muchas diferencias, se caracteriza por el control y obediencia del proletario al Estado que debe equilibrar nuevvamente el sentido del trabajo humano (ALTHUSSER, 1992:300-302) ${ }^{6}$. 
Al mismo tiempo que Marx intenta desenmascarar, mediante la sospecha, las contradicciones de la sociedad capitalista, también reconoce en ella su capacidad. El potencial de producción y de adelanto que la humanidad ha conquistado en ese tiempo ha sido incomparablemente superior al que se pudiera aspirar en cualquier otro tiempo. La burguesía es una clase prometéica 7 . A esta potencia burquesa está unida la aceleración de la historia, el apocalipsis para el proletario de la llegada de la auténtica historia: la sociedad comunista.

\section{I.2. Friedrich Nietzsche}

Para cuando Marx murió, ya el joven Nietzsche había escrito varias de sus obras más importantes. Durante su etapa de admiración francesa y la

siguiente de admiración y dependencia de Wagner, Nietzsche va $\mathrm{a}$ ir asentando su propio pensamiento que inevitablemente lo conduce a la soledad. No es el solipsismo kantiano, sino el del que sabe todo lo que tiene que pasar para que surja un hombre y un mundo totalmente nuevo ${ }^{8}$.

6 Aprovecha también para distinguir entre el sistema político que se concretó en la URSS y la auténtica teoría marxista. Para conocer un poco más el desarrollo histórico del comunismo en el siglo XX pueden consultarse, entre otros muchos: BEAUVOIR, 1997; HOBSBAWM, 2003: a partir de la página 125.

7 Curiosamente esta clase tiene en su propia esencia la matriz de su destrucción. Dentro de sí misma está la contradicción intrínseca que la destruirá. La súper producción, lograda a partir de la venta de mercancía humana en el comercio, será la causa de la crisis final del sistema capitalista, dando paso a la sociedad comunista. Lo que parece la fuerza de su pervivencia será la fuerza de su desaparición.

A pesar de la soledad del genio, Nietzsche tuvo seguidores incondicionales: véase

BATAILLE, 2001:23-31, entre otros representantes de la literatura y de las nuevas corrientes estéticas.

Conforme brota su pensamiento independiente, va apareciendo también su potente anhelo demoledor y desenmascarador. Para desarrollar libremente la voluntad de poder humana es necesario descubrir las adulteraciones de lo que la masa considera "realidad". Principalmente vamos a analizar su labor "deconstructora" en tres campos: conocimiento, valores y nihilismo.

Para Nietzsche el conocimiento tiene dos funciones principales: la de la simulación y la de cubrir la necesidad de ejercer el poder. Estas dos funciones responden a dos finalidades principales del hombre: proyectar un mundo de ilusiones e imágenes que aligeren la carga extrema del hombre por considerarse un ser limitado, débil y en peligro constante ${ }^{9}$. 
"El intelecto como un medio para la conservación del individuo, desarrolla sus fuerzas capitales en la ficción, puesta ésta es el medio por el cual se conservan los individuos más débiles y menos robustos..." (NIETZSCHE, 1996:18).

¿Cuáles son los recursos que el intelecto humano pone en juego para complementar sus dos funciones y sus dos finalidades? En primer lugar, crea metáforas o explota su potencial de simbología ${ }^{10}$;

" Un estímulo nervioso extrapolado en primer lugar en una imagen!, primera metáfora. ¡La imagen transformada de nuevo en un sonido articulado!, segunda metáfora. Y cada vez, un salto total de esferas, adentrándose en otra completamente distinta y nueva" (NIETZSCHE,

1996:44);

en segundo lugar, intenta satisfacer mediante las metáforas ciertas necesidades vitales elementales que el hombre tiene.

La verdad no es para Nietzsche una conformación entre el sujeto cognoscente y un objeto conocido, sino que cada individuo crea totalmente su realidad,

9 Esta misma obra se encuentra con otra traducción en La Jornada Semanal $n^{\circ} 301$ (10 de diciembre de 2000) 3-6.

10 El esquema de Nietzsche en su teoría del conocimiento es el siguiente: primeramente, el hombre recibe una sensaciones, las cuales son traducidas a imágenes, que posteriormente, se convierten en conceptos (moldes que igualan lo no-igual). Este proceso nos da la forma y el concepto, siendo así que en la naturaleza no existen ni conceptos ni formas, sino una $X$ desconocida.

según sus necesidades ${ }^{11}$. El error no sería más que una verdad que ya no es útil para la vida del sujeto.

"Las ficciones que han demostrado ser menos útiles que otras, o claramente nocivas, se consideran errores. Sin embargo, aquellas que han probado su utilidad para la especie y han alcanzado el rango de verdades indiscutibles, han pasado a formar parte del lenguaje" (COPLESTON,

1991:322).

La verdad, ya no es algo objetivo. La realidad se ha convertiplo en algo inasible, en una $X$ irreconocible e inalcanzable para el sujeto ${ }^{12}$. 
"Del mismo modo que el sonido configurado en la arena, la enigmática $x$ de la cosa en sí se presenta en principio como impulso nervioso, después como figura, finalmente como sonido" (NIETZSCHE, 1996:23).

Para Nietzsche los juicios sintéticos a priori kantianos se pueden reducir a juicios morales de valor. No serían propiamente condiciones subjetivas que conducían a un conocimiento cierto. Más bien, hay que considerarlo como condiciones del conocimiento, que en realidad es un enmascaramiento de la realidad, al que se llega por presión social y al que tenemos que adherirnos para poder sobrevivir. En el fondo toda la teoría del conocimiento de Nietzsche está modulada por la voluntad de vivir, por la necesidad de conservarse en la especie mediante esa lucha por el poder ${ }^{13}$.

11

Esta objetivación es la diferencia entre los animales y el hombre. El hombre es el animal mentiroso por excelencia a partir de su capacidad de elaborar metáforas a las que les da el valor consuetudinario de verdad, aunque sean pura fabricación consensuada de realidades. Todo este castillo de naipes es edificado con la única finalidad de tener poder. Estos recursos de autodefensa no se dan entre los animales, los cuales no disponen de esta racionalidad ni de esta necesidad de autoengañarse para poder sobrevivir, cf. VATTIMO, 2001:7.

12 Este texto ha de marcar definitivamente el pensamiento actual postmoderno. Algunos casos podemos encontrarlos en VATTIMO, 1998:108; DERRIDA, 1998:15-35. (Edición

cibernética: "Derrida en castellano").

13 Es curioso el contraste con el pensamiento de Schopenhauer que consideraba al impulso vital como lo más falso del instinto de conservación del hombre que estaba condenado,

como nada que era frente al no-existir, a desaparecer. Nietzsche es el defensor de la voluntad de vivir como una pulsión instintiva que obliga al hombre a luchar por su sobrevivencia con la seguridad de que la historia ha de volver a repetirse. El hombre no desaparece en la nada (Schopenhauer), sino que está anclado en un eterno retorno del tiempo que conduce a la nada (nihilismo de Nietzsche).

"La respuesta de Nietzsche es: porque en esta necesitación lógica se impone la compulsión metalógica de la historia natural, que es cabalmente la necesidad práctica de la reproducción de la vida..." (NIETZSCHE, 1996:50).

La conclusión a la que llegamos es el nihilismo. No existe un mundo verdadero. Lo verdadero se reduce a lo subjetivo que cada ser se fabrica. Desde este pensamiento no es difícil derivar en un pragmatismo vital

"Aún así, es interesante observar cómo Nietzsche se anticipa a John Dewey en el uso de un enfoque instrumental o pragmático de la verdad, incluso a la firme solidez de la verdad absoluta, tanto lógica como teórica. 
Para él, aun los principios lógicos fundamentales, son simple expresión de la voluntad de poder, instrumentos que posibilitan al hombre el dominio del flujo del devenir" (COPLESTON, 1991:323);

o en un indiferentismo total fundamentado en la subjetividad engañosa de cada quien.

La voluntad de vida es la característica principal del nuevo hombre. No es racista ${ }^{14}$, ni es el resultado de la evolución biológica. El superhombre tiene la inocencia de un niño, tiene la capacidad de crear valores, vive fiel a la tierra. Sería, en resumen, la encarnación de todo el ideal nietzscheano.

Para la aparición de esta figura se pone como condición inevitable la muerte de $\operatorname{Dios}^{15}$. Con Dios muere también el cristianismo como condensación de toda la cultura decadente que intenta renovar ${ }^{16}$. Dios representa para Nietzsche la antinomia de la vida y la negación de la inocencia del hombre.

14 Este es uno de los puntos en el que los pensadores nazis desvirtuaron la filosofía de Nietzsche. Éste odia ciertas costumbres alemanas como la cerveza y la salchicha y no cree en el germanismo. Incluso, llega a escribir líneas de admiración a favor de los judíos; cf. Ib., 146; 68. De la misma manera puede decirse que, por otro lado, expresa su admiración por la cultura francesa y su influencia en lo mejor del pensamiento alemán, véase NIETZSCHE, 1996:31; TEJEDOR CAMPOMANES, 1993:381; Vattimo, 2001:7.

15 No existe texto más explícto que el acta de la muerte de Dios que Nietzsche hace pública, a modo de relato, en la Gaya Ciencia, número 125, titulado "El Loco". Lo mismo se dice en el Aforismo 343 del mismo libro.

16 El pensamiento cristiano también ha reaccionado a las consecuencias de la muerte de

Dios, véase FORTEA, 2002:135-141. La muerte de Dios ha sido un tema recurrente hasta nuestros días. Ya Dostoievski advirtió de que con la ausencia de Dios todo estaba permitido. Sobre este tema versa todo el discurso del Gran Inquisidor de los Hermanos Karamazov. Iván sería el personaje literario que representa el nihilismo más extremoso, rayano con el anarquismo, véase DOSTOIEVSKI, 1997:XX-XXIV.

El valor cristiano que más odia Nietzsche como nocivo para la creación del nuevo hombre es el de la compasión, ya que éste eterniza al hombre en la debilidad de la antigua moralidad.

"¿Qué es lo más humano? Evitar que alguien pase vergüenza", escribió en Más allá del bien y del mal. Nada hay por lo que se deba pasar vergüenza y, sobre todo, no existe nadie que pueda arrogarse la facultad de provocar la vergüenza ajena. Ahí está el sentido de la muerte de Dios. Y así está toda la humanidad de Nietzsche. 
En haber apuntado la tremenda falsedad de las filosofía que pretenden enseñarnos a vivir. $\mathrm{Y}$ a subrayar que, en esa guerra, estamos definitivamente solos" (ROJO, 2000:12).

No hay realidad, no hay verdad, no hay Dios, no hay valores universales. Nietzsche piensa que hasta él la humanidad ha estado valorando lo que se opone a la vida ${ }^{17}$. La moral vigente procede de un espíritu enfermo y decadente. Lo que hay que hacer es una transvaloración de tal forma que favorezcan a la vida. Éste es el sentido de estar más allá del bien y del mal.

"Así pues, la moral surge como resultado de la rebelión de los esclavos, y es producto de una actitud reactiva, del resentimiento. El resentimiento creó los valores morales de occidente y es el responsable de la aparición de una civilización enemiga de la vida y de un hombre incurablemente mediocre. En resumen, es el causante del nihilismo que amenaza a occidente. Sin embargo, Nietzsche se atreve a esperar que si la lucha entre los conceptos bueno-malo (sin connotación moral) y bueno-malvado (con connotaciones morales) se ha resuelto hasta ahora con la victoria del segundo par, llegará el día en que se pueda vivir más allá del bien y del mal (lo malvado), se recobre la primitiva inocencia, y aparezca el superhombre anunciado por Zaratustra" (TEJEDOR CAMPOMANES, 1993:387).

17 Sobre el nihilismo y sus formas, véase HEIDEGGER, 2000:sobre todo el capítulo 5: "La proveniencia del nihilismo. Sus tres formas": "Ya no se detiene sólo en el sentimiento de carencia de valor y de meta del devenir, ya no se detiene sólo en el sentimiento de irrealidad del devenir. El nihilismo se convierte ahora en expresa incredulidad, en algo así como un mundo erigido „por encima" de lo sensible y lo que deviene (de lo "físico"), es decir en un mundo metafísico... No se detiene simplemente en el sentimiento de la carencia de valor de este mundo del devenir y en el sentimiento de su irrealidad".

Todo lo dicho hasta este momento lo refuerza con su idea de eterno retorno. Éste es el tema clave de su libro clave Así habló Zaratustra, sobre todo su tercera parte. La idea había aparecido ya en tiempos de los presocráticos. Concretamente Heráclito había hablado ya del eterno retorno en sentido cosmológico y cosmogónico. Sin embargo Nietzsche lo toma no precisamente en este sentido. Se opone a la idea lineal y teleológica del universo, con lo cual no admite el transmundo platónico ni el otro mundo cristiano. Éste es el único mundo. 
El eterno retorno es la suprema fórmula de la fidelidad a la tierra, del sí a la vida y al mundo que pronuncia la voluntad de poder. Con esta afirmación Nietzsche dice que todo lo que hay en el mundo es bueno y justificable, puesto que todo debe repetirse. En el fondo se entona una alabanza de sí mismo y de la existencia.

"Nunca había escrito que el dolor no formara parte de la vida. Celebraba la vida con todo el dolor que ésta arrastrara consigo. La tarea que se había encomendado había sido precisamente ésa, la de desenmascarar a todos aquellos que predicaban que lo verdaderamente importante estaba en otra parte. Ya fuera en el cielo o en el infierno, en la santidad, el heroísmo o el genio. No hay otro lugar, esto es lo que hay, parecía decir Nietzsche con cada uno de sus escritos. "Pero decidme, hermanos míos, ¿qué es capaz de hacer el niño que ni siquiera el león ha podido hacer?", se preguntaba al comienzo de Así Habló Zaratustra. Y respondía: "Inocencia es el niño, y olvido, un nuevo comienzo, un juego, una rueda que se mueve por sí misma, un primer movimiento, un santo decir sí"' (ROJO, 2000:12).

Zaratustra se convierte en el máximo profeta del eterno retorno. De esta forma la filosofía de Nietzsche se convierte en una filosofía positiva ya que todo es bueno y puede repetirse.

La otra cara de la moneda del pensamiento de Nietzsche es, además de la exposición de su filosofía, la crítica demoledora de las ramas del saber que durante muchos siglos han representado el núcleo de Europa. Tales serían: la civilización y la filosofía.

El nihilismo se define en función de la voluntad de poder, que es la esencia misma de la vida. Usa Nietzsche esta palabra con dos significados diferentes:

\section{Activo: signo del creciente poder del espíritu.}

Pasivo: decadencia y retroceso del poder del espíritu.

El diagnóstico de Nietzsche es que este tipo segundo de nihilismo está a punto de llegar. Los valores que soportaban la cultura occidental son falsos porque están en contra de la misma vida. Esos valores han creado realmente una cultura de la nada, en la que no se ha dado reconocimiento a la existencia ${ }^{18}$. 
"Apenas se consolaba con un mundo después de la muerte: su anhelo tendía más alto, más allá de los dioses, el griego negaba la existencia, junto con su polícromo y resplandeciente reflejo en los dioses. En la conciencia del despertar de la embriaguez ve por todas partes lo espantoso del absurdo del ser hombre: esto le produce náuseas. Ahora comprende la sabiduría del dios de los bosques" (NIETZSCHE, 1997:244).

De "Dios es la verdad" se pasará a decir que "todo es falso". Este tiempo no ha llegado todavía, pero está pronto. Cuando aparezca será el tiempo del último hombre que dará paso al superhombre.

Contra este nihilismo pasivo reacciona con el nihilismo activo. Éste se compone de:

$\square$ Potencia violenta destructiva contra los valores ya acabados. Los valores no se derrumban por sí solos, sino que activamente se les rechaza.

$\square$ Por otra parte, es la condición para que la voluntad de poder cree valores nuevos que abran el camino del superhombre y del amor a la vida y a la existencia.

La filosofía occidental se ha corrompido desde Sócrates y Platón. Sócrates hizo triunfar a la razón contra la vida, Apolo vs. Dioniso ${ }^{\text {. }}$

"Pese a este pesimismo práctico, Sócrates es el prototipo del optimismo teórico, que, con la señalada creencia en la posibilidad de escrutar la naturaleza de las cosas, concede al saber y al conocimiento la fuerza de una medicina universal, y ve en el error el mal en si" (NIETZSCHE,

1997:129.225).

Platón (NIETZSCHE, 1997:129.223-224) creó otro mundo desvalorizando éste, al mismo tiempo inventó el espíritu puro y el bien en sí.

Pero Nietzsche defiende que el pensamiento de un filósofo tiene su fundamento en la vida. ¿Por qué Platón y Sócrates dan este giro en la filosofía? Porque tenían miedo a los instintos, a la vida y al mundo.

18

Lo dicho hace referencia a las limitaciones del pensamiento apolíneo en contraposición con lo dionisiaco. Queda clara, por otra parte, la influencia que posteriormente Nietzsche tenga sobre el pensamiento existencialista francés.

19 En esta obra la crítica a Sócrates aparece por todas partes. 
Nietzsche no perdona nada de la tradición filosófica occidental. Pareciera que sólo libera a Heráclito. Ataca los principales conceptos metafísicos: el ser (filosofía clásica), el yo (Descartes), la cosa en sí (Kant). El mayor error de la filosofía ha sido el enfrentamiento del mundo en sí con el mundo de la apariencia. No hay más realidad que la que aparece y es aceptable por los sentidos.

Modifica el concepto de verdad. Su pensamiento es un fenomenismo: la apariencia es todo lo que hay, no existen verdades en sí. La verdad es verdadera por su valor pragmático: lo que aumenta el poder, aumenta la vida. Contra el dogmatismo metafísico defiende un perspectivismo: no hay hechos, sino interpretaciones.

"A su vez Nietzsche llamaba perspectivismo o fenomenalismo al hecho de que la naturaleza de la conciencia animal implica que el mundo de que adquiere conciencia sea sólo un mundo superficial y generalizado, pues toda conciencia se halla unida a una corrupción, falseamiento, superficialización y generalización. El conocimiento funciona, pues, de acuerdo con las necesidades vitales del ente cognoscente sin que pude pretenderse nunca una objetividad" (FERRATER MORA, 2001:2767).

\section{I.3. Estructuralismo}

En los años 60 domina en el pensamiento francés (MORERA DE GUIJARRO en

GONZÁLEZ GARCÍA 1992:517) la influencia del estructuralismo (FERRATER MORA, 2001:1125-1135) y de uno de sus predecesores: Ferdinand de Saussure (DERRIDA, 2000:39-57). Son varios los puntos positivos y varios los negativos que pueden verse en este movimiento. Pero no se puede decir que Baudrillard sea un estructuralista en el sentido pleno de la palabra, mas sí lo tiene presente desde una postura crítica.

Se reconoce en el estructuralismo la bondad de ser un pensamiento que se resiste a identificarse como un movimiento más dentro de la descripción ideal de una historia de la filosofía. El estructuralismo posee una manera distinta de enfrentarse a la historia y a los objetos, su horizonte es más amplio que el estricto del racionalismo o de la identidad. 
"Por su intención más interna y al igual que toda cuestión sobre el lenguaje, el estructuralismo escapa así a la historia clásica de las ideas, que da ya por supuesto la posibilidad de aquél, que pertenece ingenuamente a la esfera de lo cuestionado y se profiere en ella" (DERRIDA, 1989:11).

Esto se aúna con la esencial importancia que le da al lenguaje:

“... La reflexión universal reciba hoy un movimiento formidable a partir de una inquietud acerca del lenguaje -que no puede ser sino una inquietud del lenguaje y dentro del lenguaje mismo..." (DERRIDA, 1989:9).

Ambos factores, originalidad en el tratamiento de la historia e interés inédito por el lenguaje, componen la base de la originalidad del estructuralismo y hace que éste escape a una clasificación histórica de las ideas clásicas. Se resiste a reduccionismos teleológicos o causalistas que pretenden poseer una totalidad de sentido más allá de su expresión formal y concreta, creen saber sus orígenes y sus consecuencias. Ante todo el estructuralismo intenta conservar y respetar la autonomía y sentido interno de cada configuración.

"En los dominios biológico y lingüístico donde se ha manifestado primero, aquél consiste sobre todo en preservar la coherencia y la completitud de cada totalidad en su nivel propio. Se prohíbe a sí mismo considerar en primer término, dentro de una configuración dada, la dimensión de inacabamiento o de defecto, todo aquello por lo que tal configuración no parecería sino como la anticipación ciega o la desviación misteriosa de una ortogénesis pensada a partir de un telos o de una norma ideal. Ser estructuralista es fijarse en primer término en la organización del sentido, en la autonomía y el equilibrio propio, en la constitución lograda de cada momento, de cada forma, es rehusarse a deportar a rango de accidente aberrante todo lo que un tipo ideal no permite comprender. Incluso lo patológico no es simple ausencia de estructura. Está organizado. No se comprende como deficiencia, defección o descomposición de una bella totalidad ideal. No es una simple derrota del telos" (DERRIDA, 1989:41). 
Sin embargo, no todo es aceptable en los planteamientos estructuralistas. El estructuralismo acaba cediendo a la tentación de poseer un sentido último, cede ante la historicidad clásica. Esta claudicación se traduce principalmente en tres puntos: ontologización de la estructura, totalidad cerrada del plano y reducción a la idea.

No se respeta el sentido y la autonomía que se decía consideraba el estructuralismo. La estructura focaliza todas las atenciones y ocupa el lugar de loppás profundo, se solidifica lo profundo en la superficialidad ontológica ${ }^{20}$.

"Aquí la estructura, el esquema de construcción, la correlación morfológica se convierte, de hecho y a pesar de la intención teórica, en la única preocupación del crítico. Única, o poco menos. No ya método en el ordo cognoscendi, no ya relación en el ordo essendi, sino ser de la obra. Estamos tratando con un ultra-estructuralismo" (DERRIDA, 1989:27).

Incluso el sujeto que tanta importancia había tenido en la historia de la filosofía se sumerge como algo más dentro de la estructura; la centralidad del sujeto se sustituye por la estructura 21 .

Por otro lado, las dimensiones diversas de la realidad, del tiempo se reducen a dos: espacio morfológico y geométrico, orden de formas y lugares.

"En esta exigencia de lo llano y de lo horizontal, lo que es intolerable para el estructuralismo es ciertamente la riqueza, la implicación del volumen, todo lo que en la significación no puede estar expuesto en la

20 Véase también lo que afirma Derrida a este respecto en la página anterior de esta misma obra.

21 Véase MORERA DE GUIJARRO, en Moisés GONZÁLEZ GARCíA 1992:532; FOUCAULT,

1990:86; y ARROYO, 2004:24.

La misma idea aparece en otro estructuralista insigne: "El fin último de las ciencias humanas no consiste en constituir al hombre, sino en disolverlo", LÉVI- STRAUSS, en REALE-ANTISERI, 1995:826. Del mismo parecer es la teoría sistémica de Luhmann: "That we have to name two concepts -center and top- has its reasons that lie concealed in the old European tradition and are connected with their distinctions of ethics and politics. 
In connection with this Aristotelian distinction, social ethics was worked out as the theory of frienship directed towards a center, towards a heightened, increased, perfect friendship that would exist only for paradigms of virtue (Panaitions, Cicero). The theory of political society (societas civilis) remained, with its idea of order, hierarchically structured. The difference itself may have had semantic function in diffusing attention. In any event, it leaves behind the possibility of formulating what we lack in modern society as the center or top", LUHMANN, 1990:31-32, nota 9. "Human beings, concrete individual persons, take part in all social systems. But they do not enter into any of these as determinate parts themeselves or into society itself. Society is not composed of human beings, it is composed of the communication among human beings. It is important to keep this starting point in mind. It distinguishes the systemstheoretical theory of society from the older tradition of political thought and forms an indispensable condition for an analysis of the environmental relations of the system of society and its subsystems- an analysis on which we decisively depend", LUHMANN, 1990:30. Véase también todo lo que McLuhan habla respecto al espacio acústico en contra del espacio euclidiano: éste es lineal y mecánico, aquél no tiene centro, es esférico y es eléctrico; véase MCLUHANPOWERS, 1996:133-137.141. En la misma línea se argumenta en LYOTARD, 2003:89. simultaneidad de una forma. Pero, ¿es un azar que el libro sea en primer lugar volumen?" (Derrida, 1989:39).

Para el estructuralista literario la letra solamente expresa lo dicho en las tablas, se anula el movimiento, la inestabilidad del sentido enrollado sobre sí mismo.

Por último, la reducción del sentido a una idea desvirtúa la potencia de la génesis y de la fuerza. Esta reducción no es sino un formalismo como lo que quería olvidar en sus principios el mismo estructuralismo. De esta manera puede ocupar un lugar más dentro de la historia heliocéntrica de la metafísica tradicional.

En definitiva, el estructuralismo olvida la fuerza en su sentido más originario, más nietzscheano, para reducir todo su empuje a la significación, a la forma. Como ya denunciara Nietzsche desaparece en la filosofía lo dionisiaco para dominar lo apolíneo. 
Se opacan las diferencias y el núcleo más profundo de las cosas (NIETZSCHE, 1991:132; MANZANO, 2002:13-24). Es imprescindible para nuestros días el equilibrio entre los dos polos, no como alternativa u oposición, sino como diferencia ${ }^{22}$ generadora de cambios y riqueza desde la variedad.

"El litigio, la diferencia entre Dionisio y Apolo, entre el impulso y la estructura, no se borra en la historia, pues no está en la historia. Es también, en un sentido insólito, una estructura originaria: la apertura de la historia, la historicidad misma. La diferencia no pertenece simplemente ni a la historia ni a la estructura" (DERRIDA, 1989:44).

Hemos visto cómo decaen durante el siglo XIX gran parte de las ideas que sostenían una cosmovisión (Weltanschauung) (KLEMPERER, 2002:210-213) determinada del mundo. Se delatan las contradicciones de la nueva sociedad burguesa y todo lo que ella conlleva (GONZÁLEZ DE CARDEDAL, 2004:3), de la idea de Dios, de los valores clásicos, de la firmeza en el principio de identidad ${ }^{23}$, de la solidez del individuo ilustrado (FOUCAULT, 1968;333.375;

\footnotetext{
22 "Pero Derrida está en la línea heideggeriana, contra la metafísica de la presencia. La presencia dice, de manera cercana a Lacan- es mera ilusión. Es la que está vinculada a la identidad. Por eso Derrida exalta la diferencia, a la cual, para que tenga tanto el sentido de lo diferente como de lo diferido, la llama différance (que ha sido puesto en castellano como diferancia o diferenzia)" (BEECHOT, 2004:175.1)

23 A su estilo y desde su perspectiva Levinas da un giro rotundo respecto al principio de identidad y se fija mucho en la otreidad o, dicho con las reservas apropiadas, en la diferencia o

en la negación de la identidad, véase LEVINAS, 2000. Dígase los mismo del pensamiento de ZAMORA, 2003:231-243) ${ }^{24}$, de la seguridad de la conciencia (GIDE, 2004:67-

$75)^{25}$, de la caída de la metafísica tradicional ${ }^{26}$, de toda la cultura clásica

occidental...(SCHERPE en PICÓ, 2002:352).
}

Si a todo lo visto añadimos las teorías sobre los medios de comunicación (MacLuhan, respetando sus muchas diferencias, y posteriores desarrollos), las teorías del caos, de los fractales, la rapidez de avances científicos, la fortaleza de lo que etéreamente se denomina como postmodernismo... podemos hacernos una idea somera de lo que pudiéramos clasificar como matriz o corriente, muy general, de pensamiento en la que se mueve Baudrillard. No se puede negar la originalidad del autor francés, pero sí podremos ver que se le entiende mejor desde este referente histórico. 


\section{MATRIX RE-LOADED}

La sociedad actual puede, pues, analizarse genéticamente desde la matriz remota arriba mencionada. En esta misma corriente silente de teoría crítica habría que sumergir el pensamiento de Jean Baudrillard. Éste se inscribe en el lado oscuro de la modernidad. Su mundo padece de una desilusión aguda de lo social, de un vaciamiento del símbolo, del apagamiento del sujeto histórico ${ }^{2}$, de la ilusión de la seducción.

Su obra pone en tela de juicio las finalidades referenciales y se instala en la observación apática de la profundidad inagotable llena de referencias libres dentro de una sociedad simbólica y seductora. Es tan rica esta profundidad, combinada con la celeridad de los cambios, que su resultado se convierte en 1996:14) un proceso incontrolado de implosión moderna (MCLUHAN-POWERS

de autodestrucción de la sociedad desde sus mismas fortalezas.

\section{1. TRANSFORMACIÓN DE LO SOCIAL EN MASA}

Desde el siglo XIX se comienza a realizar un estudio sistematizado respecto a la sociedad como objeto de ciencia particular. A. Comte, M. Weber, E. Durkheim, K. Marx, J. J. Rousseau... son autores que estudian la sociedad como algo propio, con sus leyes, etapas y dinámicas definidas. Recogen las

Adorno, véase MENDIETA, HABERMAS, 2001:23-24; también CORTINA, 1994:42-72. Desde un punto de vista más existencial y literario, KERTÉSZ, 2002.

24 Para la noción de no-persona véase en MCLUHAN-POWERS, 1996:143.

25 La reacción de Prometeo al comerse su águila (conciencia) es la ironía y la risa.

26 Sobre la caída de la metafísica tradicional y sobre la influencia de Heidegger en este fenómeno, yéase ARENDT-HEIDEGGER, 2000:173.

27 El opacamiento de la centralidad del sujeto de la que ya hablamos más arriba y que desde otro punto de vista vamos a ver en este apartado, tiene uno de sus fundadores, desde un

punto de vista existencial y epistemológico, en Heidegger, véase SAFRANSKI, 2003:132.

inquietudes y los avances que respecto a la importancia del pueblo y de las masas se descubren a lo largo del sangriento siglo XVIII. Participación popular, Asambleas Representativas, ampliación del concepto de tolerancia (LOCKE, 1994), la reconsideración sobre el uso público y privado de la razón (KANT , 2001:287-291), primeros pasos definitorios de los derechos humanos ${ }^{28}$, moral civil (CORTINA en GALINDO, 1993:41-56) ... son conceptos que preparan la identidad de una ciencia que se centra en la sociedad y no en los mandos gobernantes de un tipo $u$ otro. 
Sobre esta vasta base aparece en las primeras décadas del siglo XX el pensamiento de José Ortega y Gasset $^{29}$. La importancia de los periódicos, la generalización de noticias, el derecho asumido de la huelga, las aglomeraciones de personas, ciertos cambios de comportamientos... son indicadores que llevan al autor madrileño a desarrollar el cambio del concepto "gente" al de "masa"30.

"El concepto de muchedumbre es cuantitativo y visual. Traduzcámoslo, sin alterarlo, a la terminología sociológica. Entonces hallamos la idea de masas social. La sociedad es siempre una unidad dinámica de dos factores: minorías y masas. Las minorías, son individuos o grupos de individuos especialmente cualificados. La masa es el conjunto de personas no especialmente cualificadas. No se entienda, pues, por masas, sólo ni principalmente "las masas obreras". Masa es el "hombre medio"... es la cualidad común, es lo mostrenco social, es el hombre en cuanto no se diferencia de otros hombres, sino que repite en sí un tipo genérico" (ORTEGA Y GASSET, 1995:76; ORTEGA Y GASSET, 1981:275-287).

Todos ellos reflejan, a manera de indicadores, las consecuencias que una mayor distribución y abundancia de dinero han provocado en la sociedad burguesa.

El dinero es sinónimo de mayor comodidad, cuando menos de unos cuantos. Pero no es lo mismo que posesión de cultura, educación y sentido crítico. Esto es lo que Ortega avisa: la fuerza de una mayoría más acomodada, que no siempre es una mayoría más preparada. El espíritu gregario, anónimo, es una

28 Declaración de Filadelfia en 1776, Declaración de los derechos del hombre y del ciudadano en 1791, Constitución francesa de $1793 \ldots$

29 Una introducción somera y contextualizada, véase. MARÍAS, 1983:217-263.

30 Véase JUARISTI, 2005:8.

de las características más representativa del hombre-masa tan creciente en

Europa ${ }^{31}$.

"Triunfa hoy sobre todo el área continental una forma de homogeneidad que amenaza consumir por completo aquel tesoro. 
Dondequiera ha surgido el hombre-masa de que este volumen se ocupa, un tipo de hombre hecho de prisa, montado nada más que sobre unas cuantas y pobres abstracciones y que, por lo mismo, es idéntico de un cabo a otro de Europa... carece de un "dentro", de una intimidad suya, inexorable e inalienable, de un yo que no se puede revocar" (ORTEGA Y GASSET, 1995:49).

Sobre el marco general del paradigma sociológico, fundamental en el siglo $\mathrm{XX}$, se destacan las dificultades orteguianas $\mathrm{y}$, posteriormente, las de otro tipo de pensamiento totalmente diferente como es el de Baudrillard. Baudrillard es claro a la hora de declarar la muerte de lo social (PICÓ,2002:11). No es que haya sido superado por otro enfoque diverso, que haya desaparecido la importancia de la sociología, sino que la masa, producto de la misma sociedad, por su propia densidad, ha originado la implosión de lo social.

La masa se convierte en un conjunto de elementos vacíos que saltan por encima de cualquier discurso normativo, o de cualquier sistema referencial, o de cualquier narración histórica (BAUDRILLARD, 1998:38). La socialidad racional del contrato, la socialidad dialéctica, da paso a la socialidad del contacto, del circuito, de las redes en donde millones de moléculas se relacionan de manera 3 aleatoria y permanente sin tener en cuenta finalidades ni homeostasis ${ }^{32}$.

Partiendo de este vacío no es de esperar histeria o fascismo potencial (LIPOVETSKY, 2000:36-45; SAFRANSKI, 2002:21) 33 . La respuesta de la masa es la simulación que se presenta cuando los discursos positivamente normativos desaparecen.

31 Véase página. 49 sobre la mutua influencia entre la masa y el lenguaje; 60-61 sobre la relación entre la política y el hombre-masa.

32 Es similar esta idea a la "différance" o "diferancia", que utiliza Derrida: véase DERRIDA, 1998; DERRIDA en Peretti, 1997:23-27.

33 La hipnosis proveniente desde los mass media y la falta de compromiso en todos los sentidos, da como resultado un sentimiento difuso de apatía, característico de la denominada

postmodernidad. Aunque, adelantamos, el concepto de apatía de Baudrillard no es idéntico al de Lipovetsky. 
"Cuando lo falso recupera toda la energía de lo verdadero, o a la inversa, nos encontramos con el arte, con la ilusión. Cuando lo real absorbe toda la energía de lo irreal, nos encontramos con la ficción. Por el contrario, cuando lo verdadero pierde incluso su energía inversa, la de lo imaginario, nos encontramos con la simulación, el grado más bajo de la ilusión. Cuando el bien pierde incluso la energía del mal, nos encontramos con el grado más bajo de la moral" (BAUDRILLARD, 1998:11-12; BAUDRILLARD 1993:29).

La cultura de la significación se abre paso mediante el declive de la tradición sociológica que tan importante fue a comienzos y durante todo el siglo XX. La sociedad reificada, que se podía alcanzar mediante las ciencias sociales, se convierte en un sistema libre y abierto de signos que favorece la simulación. La auténtica realidad resulta ser la hiperrealidad que desde lo oscuro va guiando lo que pensamos es la verdadera realidad.

"Sobre todo cuando se llega... a la descomposición digital (binaria) de los mensajes. Porque la digitalización es un formidable instrumento de descomposición-recomposición que realmente fragmenta todo. Para el hombre "digigeneracional" (el hombre de cultura digital) ya no existe una realidad que "se sotenga". Para él cualquier conjunto de cosas puede ser manipulado y mezclado ad libitum, a su gusto, de miles de formas" (SARTORI, 2003:43 nota 13.41.62.64.99.113.190; LIPOVETSKY, 2003:106; ARGULLOL, 2004:13).

Es el juego de la computerización cibernética, que disfraza su información de fondo fundamental en la diversidad incuestionable e inacabable de funciones. Lo que tradicionalmente consideramos como realidad tiene las características para Baudrillard de la diferenciación y de una relación estrecha entre el sujeto y el objeto. La hiperrealidad se caracteriza por poseer un universo integrado y por la ausencia de relación entre sujeto y objeto. La tecnología es la causante de la revolución actual de todas las acciones posibles dentro de la virtualidad y de la conversión de lo real en hiperrreal, de lo diferenciado en integrado, de lo tangible en virtual. El sujeto pasa a la sombra de la acción, por no decir que es totalmente eliminado ${ }^{34}$. 
Sobre todo lo dicho en este párrafo se puede encontrar una referencia en la "prima domanda" de este mismo artículo.

"In questo universo il soggetto non ha più una sua posizione propria, una condizione vera, in quanto soggetto, di un sapere o di un potere o di una storia. C"é invece un"interazione, che vuol dire in fin dei conti uno svolgimento o un riavolgimento di tutte le azioni possibili. Nella relata virtuale tutto é effettivamente possibile, ma la posizione del soggetto é pericolosamente minacciata, se non eliminata" (BAUDRILLARD, 1999:1).

Éste es el contenido del crimen perfecto de nuestros días.

"Esto es la historia de un crimen, del asesinato de la realidad. Y del exterminio de una ilusión, la ilusión vital, la ilusión radical del mundo. Lo real no desaparece en la ilusión, es la ilusión la que desaparece en la realidad integral" (BAUDRILLARD, 2000:9).

La sociedad se ha sofisticado tanto y se ha tecnificado de tal manera, que el hombre se siente fuera de ese mundo tan perfecto, artificial y esterilizado (ARENDT-HEIDEGGER, 2000:228.223.231; BAUDRILLARD, $1999: 4)$.

Su extrañamiento es parte de la impotencia cínica que muestra ante el proceso de e(in)volución. Se convierte en el entorno prescindible de un tipo de socialidad imprescindible (ISLA, 2003).

La saturación y la retractación en los sistemas estelares es el ejemplo que Baudrillard utiliza para describir esta peculiar y descontrolada dinámica de la sociedad.

\section{2. La negación del sujeto histórico}

Valor de uso, sociedad normalizadora, sociología, razón dialéctica, historia, producción de significado... son algunos de los términos que utiliza Baudrillard para hablar de la sociedad que busca un orden estable, controlada por un poder del que ya hablamos más arriba. Entre estos conceptos incluye también su crítica a la política. 
Los principales ideales sobre los que se ha movido la política en los últimos tiempos están fundamentados en la comprensión del valor de uso como campo, universalmente accesible, de verdad. La teoría de la producción marxista, por ejemplo, se sostiene sobre el supuesto falso de la producción del sujeto histórico emancipado como algo deseable y que está en sus propias posibilidades.

"Pero lo hizo en nombre de la emergencia en acto de la fuerza de trabajo, de la fuerza propia del hombre de hacer surgir valor por medio de su trabajo („pro-ducere'), y cabe preguntarse si no hay aquí una ficción análogo, una naturalización análoga, es decir, una conversión igualmente arbitraria, un modelo de simulación destinado a codificar todo material humano, toda eventualidad de deseo y de intercambio en término de valor, finalidad y producción... se trata de una gigantesca elaboración secundaria que alucina en términos racionales esa predestinación del hombre a la transformación objetiva del mundo (o a la "producción" de sí mismo tema humanista hoy en día generalizado : ya no se trata de "ser" uno mismo, se trata de „producirse" a sí mismo, desde la actividad consciente hasta las „producciones"salvajes del deseo)” (BAUDRILLARD, 1984:11; BONETTI, 1995:2-6).

En el uso de expresiones como "valor de uso", "valor de cambio"... aparece muy clara la alusión al pensamiento marxista. Para él, el valor de uso junto con el valor de cambio se presentan como dos aspectos diferentes de la mercancía: el primero, implica su utilidad para ciertos agentes, que es lo que permite que la mercancía partícipe en el intercambio; el segundo, se refiere a poder disponer de ciertas cantidades de otras mercancías en intercambio. El valor de uso no es el centro de las investigaciones de Marx; da más importancia al valor de cambio porque afecta al proceso de deshumanización en el hombre. Justamente el pensamiento baudrillardiano sobre la polítiça comienza por eliminar al sujeto histórico y sus ansias emancipadoras ${ }^{35}$.

"El objeto ha sido para mí la „contraseña" por excelencia. Desde el comienzo, elegí ese ángulo porque quería desentenderme del problemática del sujeto...en los años sesenta, el paso de la primacía de la producción a la del consumo situó los objetos en un primer plano... lo que me ha interesado realmente no es tanto el objeto fabricado en sí mismo como lo que los objetos se decía entre sí, el sistema de signos y la sintaxis que elaboraban. 
$\mathrm{Y}$, por encima de todo, el hecho de que remitían a un mundo menos real..." (BAUDRILLARD, 2002:13.57).

Su pensamiento se adentra, más bien, en los procesos de deshistorización.

35 Véase CARRILLO DE ALBORNOZ, 2002:3; BAUDRILLARD, 1984:12; METZ, 2002:162164; GONZÁLEZ FAUS, 1997:11-12; ROBINSON, 1997:8-17.

"Baudrillard ha visto en la ahistoricidad de esta sociedad postmoderna un parodia del instante mesiánico convertido ya en real... El pensamiento postmoderno se presenta así como un intento de vislumbrar el futuro desde un mundo en el que ya ha ocurrido todo y ninguna utopía o razón queda por venir. La fuerza y plenitud de las cosas está en el presente, que se convierte en fugaz apariencia para el individuo y eterna representación para una humanidad en la que lo siempre nuevo se convierte indefinidamente en siempre los mismo. Desaparece así el concepto de historia como progreso de la razón y de transformación social, y se convierte en un presente cuya última finalidad es su propia reproducción" (PICÓ, 2002:48-49).

Y desocialización propios de la estructura de la sociedad mediatizada en la que vivimos.

En la novedosa cultura moderna, la colectividad política está compuesta por los medios de masas como simulacro. Lo que se intercambia es una sobreabundancia de información abstracta e hipersimbólica absolutamente desfondada(VATTIMO, 1994:161-181; YEHYA, 2003:40). Lo que está en juego es la máxima producción de significado y palabras para unos sujetos históricos que son, a la vez, sujetos y efectos del orden de simulacro. Como se puede ver, sobre las categorías marxistas de análisis, se superpone una materialidad totalmente distinta que nos conduce a otro tipo de sociedad. Está claro que lo que interesa a Baudrillard es la sociedad manipulada y el sujeto alienado por los medios de comunicación masivos electrónicos, especialmente por la televisión ${ }^{36}$.

"En cualquier caso, tendremos que padecer este nuevo estado de cosas, esta extroversión forzada de toda interioridad, esta inyección obligada de toda exterioridad que significa literalmente el imperativo categórico de la comunicación" (Baudrillard, 2002:196).

Las consecuencias estratégicas de la televisión como sociedad pudiéramos resumirlas como siguen: 
36 Uno de los casos recientes y paradigmáticos es la manipulación de la Guerra del Golfo y de la posterior invasión a Irak: véase YEHYA, 2003; AA. VV., 2003; BAUDRILLARD, 2001.

1. nebulgsa hiperrealidad de las masas, ¿Quién es y quién maneja las masas? ${ }^{3}$.

2. comunicación escenificada como marco excelente para el sistema de poder.

3. generalización y explosión de la información combinada con la implosión y vacuidad de significado.

4. comunicación irreversible que no produce respuestas (XIRAU, 2004:2); el emisor puede convertirse en receptor y viceversa.

Los medios producen y son parte de un proceso cerrado e irreversible, produciendo y reproduciéndose según una lógica moebiana aplastante. Generan significado y disparate, manipulan igualmente en todos los sentidos. Transmiten simulación interna, que se convierte en la simulación que deviene en peligro para el mismo sistema.

"Los ciudadanos no deciden conscientemente ver la televisión. Lo hacen por una especie de atracción, de hipnosis aturdida. Cada uno de ellos es un punto intermedio en el circuito, o en ese anillo de Moebius de la información" (BAUDRILLARD 1998:56).

Los medios crean las masas, producen proyectos industriales para las masas y dependen de los análisis de opinión de masas, que a su vez están dirigidos por los mismo medios (INNERARITY, 2004). Y, parece, esto es lo que gusta a los telespectadores (SARMIENTO, 2004:36-38). La nueva información de los medios electrónicos, con su prodigalidad y celeridad, destruye el significado o lo neutraliza (HOBSBAWM, 2003:376.378). Lejos de conducir a una acumulación de significado, siguiendo la imagen marxista de la plusvalía,resulta la destrucción de cualquier sistema de significado coherente. 
El mundo real se convierte en medio y el mundo "real" tiene dentro de sí mismo toda la irrealidad de la sociedad informatizada.

37

No faltan noticias provistas de credibilidad que hablan documentadamente de reuniones organizadas en secreto por ciertos poderes para acordar medidas de índole mundial, véase ESTULIN, 2004:10-16;17-22. Lo mismo pudiera decirse, por ejemplo, de las más abiertas y conocidas reuniones que tienen lugar en la localidad suiza de Davos.

"Parece que esta obsesión por el paso a la acción determina en la actualidad todos nuestros comportamientos: temor obsesivo a todo lo real, a cualquier acontecimiento real, a cualquier violencia real, a cualquier goce demasiado real. Contra esta obsesión por lo real hemos creado un gigantesco dispositivo de simulación que nos permite pasar a la acción in vitro (hasta resulta cierto para la procreación). A la catástrofe de lo real preferimos el exilio de lo virtual, cuyo espejo universal es la televisión" (BAUDRILLARD, 2001:16).

Ante esta situación, Baudrillard ofrece dos alternativas políticas.

1. Resistencia como sujeto. La respuesta del sujeto histórico autónomo que asume la lucha desde un código universal de valores y pugna por liberarse, oponerse y expresarse de forma distinta a la de los medios. Pero las exigencias emancipatorias de los sujetos históricos responden a los ordenamientos de los propios mass media. Los medios nunca van a defender que el estar sometido sea bueno, ellos se convierten en los pioneros de la libertad duradera, autenticidad y dignidad de la persona. Su intención es, desde el interior del mismo lenguaje y significado, vaciarlos de contenido.

2. Resistencia como objeto. Esta es la propuesta particular de Baudrillard para combatir el simulacro. En un sistema construido sobre el poder y la seducción (Baudrillard 2002:32-33) y que resulta cínico en su ejercicio de vacuidad significativa, la mejor resistencia es situarse a distancia de manera igualmente irónica38.

La primera resistencia, efectivamente refuerza las intenciones del sistema, arguyendo razones que el mismo sistema proporciona. La segunda, no lo cambia, pero se opone mediante actitudes contrarias que no dan más fuerza a la realidad mediática.

Baudrillard manifestará su admiración por las nuevas generaciones que manifiestan su inconformismo de manera simulada e hiperconformista. 
Este es el punto en donde, como ya dijimos, se separan la apatía de Lipovetsky y la apatía refraccionaria baudrillardiana. Aquélla procede de la atonía y saturación del individuo. Ésta es una manera de resistencia frente al sistema que quiere universalizar su realidad.

La ironía ${ }^{39}$ y la neutralidad son las maneras de no combatir efectivamente la lógica política del sistema con las mismas herramientas que el sistema ofrece para, en último término, mantenerse.

\section{3. Rechazo de la razón dialéctica}

En el tema del poder sucede de manera muy similar a como ha venido razonando Baudrillard. Para él el poder real actual es un poder muerto, que tiene su basamento en la desaparición de todos los sistemas referenciales anteriores. Se trata de un poder vacío, no de un poder que se impone y expande.

El poder soberano es el que pretende hallar una sustancia, una verdad y una legitimidad en la voluntad del pueblo. De esta misma manera pierde su soberanía al permitir que otros cuestionen su vida. Es el juego fatuo de las elecciones en los gobiernos democráticos. Pueden morir por las mismas razones por las que subió al poder. El poder reside en quien lo puede ejercer de manera real, no en quien se cree sustancia.

En su alegato contra Foucault, Baudrillard presenta un poder vacío reversible, enteramente relacional, cíclicamente intercambiable. La crítica que le hace consiste básicamente en amaestrar el poder, en querer ponerle límites acercándolo a sus referentes. Foucault malinterpreta la cualidad relacional del poder moderno.

El poder del sexo o de la sexualidad es la fuerza de algo que actualmente se está derrumbando. Si el sexo actual también ha entrado en su fase virtual, se vanaliza la seriedad de los estudios foucaultianos hacia algo propio de la historia pasada.

El secreto del poder actual reside en su relación con la nada, con la muerte. La finalidad no es acumular o sostener el poder, sino ofrecerse como simulación de nada. Se trata del poder sin principio de realidad, del poder como desafío o desafío del poder moderno.

Este enfoque está mucho más cercano al pensamiento nihilista nietzscheano que al de los estructuralistas franceses. El poder, en definitiva, es un signo de lo que nunca fue, es una simulación de una unidad abstracta que se impone a nuestra experiencia.

Desapareciendo la representacionalidad clásica del poder sociológico (poder/norma), del poder político (poder/soberanía) y del poder económico 
Como ejemplo de ironía metodológica frente a la aparente seriedad de los comerciales, véase MARX, 2004:188; SAVATER, 1995:238-239. "Lo direi in vece che la mia è piuttosto una posizione ironica in rapporto ai media", BAUDRILLARD, 1999:5-6.

(poder/mercancía), solamente queda el poder de nada, su referencia es la nada. En esto consiste el lado oscuro del ejercicio de poder moderno. El poder muerto se mantiene entre el cambio y la rescisión.

Baudrillard descubre con sorpresa y para su sorpresa que el poder más cínico, omnímodo, exclusivamente relacional y simulador que haya podido existir ha sido el fascismo. Por un lado, el fascismo ha sido los suficientemente fuerte como para arrasar con los referentes consuetudinarios de su tiempo. Por otro, podría ser la única forma actual de poder fascinante porque sería capaz de volver a subvertir los valores y generar un finiquito axiológico.

\section{4. El eclipse de la forma-mercancía}

Marx ya estableció y desenmascaró la obscenidad de la mercancía. Era visible la obscenidad de ésta cuando el precio que la libre circulación imponía era equivalente o mayor que el valor de uso del mismo objeto que se ofrecía en el mercado (plusvalía). La obscenidad radica en su abstracción y formalidad, frente al peso y sustancia del objeto.

"Puede que la definición de la obscenidad sea el devenir real, absolutamente real, de algo que, hasta entonces, estaba metaforizado o tenía una dimensión metafórica...Cuando las cosas devienen demasiado reales, cuando aparecen inmediatamente dadas, realizadas, cuando nos hallamos en ese cortocircuito que hace que tales cosas se aproximen cada vez más, nos hallamos en la obscenidad..." (BAUDRILLARD, 2002:35-36).

La mercancía es transparente frente al secreto del objeto, su obviedad es su precio. A través de su valoración monetaria entran en contacto todos los objetos. Es por eso que la mercancía es el primer gran medio de la modernidad. Esta mediación tiene, por otra parte, diferente efecto: al mismo tiempo que pone en relación todo por el precio, reduce al extremo su valoración y, por tanto su significado. 
El mensaje, en el fondo, ya no existe, es el medio quien se impone en su pura circulación, en su puro intercambio. A esto Baudrillard lo denomina como éxtasis.

Permanece, como puede verse, en diálogo cercano y fecundo con el pensamiento original marxista. Sigue sus huellas y realiza la crítica que desde la actualidad impelen las nuevas circunstancias 40 .

40 Es curioso cómo se hacía este mismo análisis en una plática que dictó MARCEL, 1967:35-72.

"Basta con prolongar este análisis marxista, o llevarlo hasta el segundo o el tercer poder para comprender la transparencia y la obscenidad del universo de la comunicación, que deja muy detrás de él aquellos análisis relativos del universo de la mercancía. Todas las funciones abolidas en una sola dimensión, la de la comunicación. Ese es el éxtasis de la comunicación. Todos los secretos, espacios y escenas abolidos en una sola dimensión de información. Eso es obscenidad" (BAUDRILLARD 2002:194).

La originalidad teórica de nuestro autor obtiene sus primeros brillos cuando aprovecha la ruptura epistemológica, dentro de la estructura de la acción social, que acontece cuando el objeto de la investigación pierde sus referentes objetivos.

Se desenmascara y aligera el peso de la "producción" como esquema material del orden industrial y real. Adquiere importancia dominante la presencia de la "simulación" dentro de un nuevo código ("lógica de la significación") articulada con la ley estructural del valor. Su pensamiento se va a desarrollar dentro de la relación estratégica de estos dos polos de desarrollo postmodernos desde los planteamientos de la modernidad.

Discute la concepción normalizadora de lo social porque apuesta por un esquema comunicacional de semiurgia radical; abandona la simplificación reductora de significado efectuada por las conveniencias culturales para someterse a la libertad de la lógica de la significación de nuestros días; la norma universalizadora y equilibrante cede ante el poder del abismo insondable y sorprendente que es el signo. 
La descripción del signo como centro dinámico de la cultura actual es de libertad absoluta, al azar, tautológica y homóloga.

La idea principal de Baudrillard, en definitiva, es que debemos volver la mirada hacia la gran revolución en el orden de los signos, hacia una lógica de significado abstracta, semiúrgica y fungible. Todo esto si es que queremos ofrecer una explicación realista de la fusión de economía, política y sociedad en nuestros días.

La presencia del signo como "lugar de lo real" indica que la preocupación postestructuralista por la operaciones semiúrgicas de la sociedad de consumo, por la referencia entre significante y significado como espejo de la producción, por la semiótica de cambio dentro de la economía, es insuficiente (BEUCHOT, 2004:161-177). Ésta radica en que la teoría del signo tiene la finalidad de responder críticamente al modo productivista del esquema industrial desde su opuesto, desde lo inasible del cambio aleatorio.

El signo, para Baudrillard, sería la expresión más pura de la heteronomía que tanto ya ha aparecido. Ésta es la gran aportación al tema del autor francés.

El esquema productivo capitalista se fundamenta en la preferencia y justificación de la importancia del valor de uso sobre la abstracción y fungibilidad del intercambio. En el esquema simulatorio avanzado de la sociedad capitalista, tanto el valor de uso como el valor de cambio, tanto el significante como el significado, pasan a formar parte de un equilibrado proceso generador semiológico.

En este último contexto la labor de Baudrillard consistirá en el análisis crítico de la cultura contemporánea y en la liberación relacional y objetivo de los referentes semiúrgicos. El signo será, entonces, esa parte oscura y oculta que desvela un parcela auténtica-desaparecida de la realidad y que no es reducible a lo que cotidianamente se denomina como realidad. El signo es un poder muerto que nace de la burla de su función como centro de una lógica estructural básica de la forma-mercancía.

Se libera al signo de su dependencia referencial con los objetos reales para jugar con la libertad relacional del signo en sí, sin referencia a algo determinado. Esto último era el centro de la lógica estructuralista del sistema capitalista avanzado. 
"Beninteso, dico questo non per nostalgia di un oggetto perduto, anche se da un punto di vista existenziale I"abbiamo effettivamente perduto, ma in base a termini dettati da una sittuazione diversa, del tutto originale, della quale però non abbiamo i mezzi per poterne prefigurare compiutamente le conseguenze" (BAUDRILLARD, 1999:2).

Para Baudrillard esta ausencia de referencialidad y de prodigalidad de intercambio sin objeto conduce a un ciclo de intercambio que inevitablemente lleva a la regresión, a la implosión. Queda bosquejado el efecto desintegrador de la experiencia contemporánea.

\section{Matrix $\operatorname{Re}$ (in)-volutions}

"No hay retorno. Todo ha terminado" 41 . Frases como éstas se repiten con frecuencia como resultado de los análisis a distintos niveles de la realidad. En

41 Inscripción en un pizarrón de aula perteneciente a la escuela de Pripiat, lugar cercano a Chernobyl. Está fechado el 28 de abril de 1986, después del fallo de seguridad de esta famosa central nuclear. Para estos estudiantes, para esos habitantes todo había terminado. Se enfrentaban a la fuerza demoledora y sorprendente en aquel momento de la muerte.

torno al año 2000 se recapitulaban respuestas de este tipo ante la incertidumbre del rumbo de la humanidad en esas fechas. Nada de esto es nuevo. En distintos momentos de la historia de la humanidad se ha jugado con el temor al fin, con la (in-)certidumbre de que todo acababa, con la forma interna de entender los distintos momentos del tiempo, con la finalidad y existencia de la historia.

El fin, tal y como lo entiende Baudrillard, es el objeto de interés en este apartado. Nuestro autor va un poco más allá de estos comentarios milenaristas que todos hemos escuchado como preanuncios de algo real que acontecerá cuando menos lo esperemos. Va más allá de la ilusión de un fin:

"A través de eso mismo, entramos, más allá de la historia, en la ficción pura, en la ilusión del mundo. La ilusión de nuestra historia desemboca en la ilusión mucho más radical del mundo. Ahora que hemos cerrado los ojos sobre la Revolución, ahora que hemos roto el Muro de la Vergüenza, ahora que las bocas de la contestación se han cerrado (con el azúcar de la historia derritiéndose en la lengua), ahora que ni el espectro del comunismo, tampoco el del poder, obsesionan a Europa y a las memorias, ahora que la ilusión aristocrática del origen y la 
ilusión democrática del fin se alejan cada vez más, hemos dejado de tener la elección de avanzar, de perseverar en la destrucción actual o de retroceder, sólo nos queda la de afrontar esta ilusión radical" (BAUDRILLARD, 1993:184).

\section{1. ¿QUIÉN QUIERE VIVIR PARA SIEMPRE ["WHO WANT LO LIVE FOR EVER']?}

"Esta compulsión de inmortalidad, de una inmortalidad definitiva, gira en torno a una locura singular: la locura de lo que ha alcanzado su objetivo. La locura identitaria, locura de saturación, de compleción, de repleción. También de perfección. La ilusión mortífera de la perfección... Si los objetos ya no envejecen con nuestro trato, es que estamos muertos" (BAUDRILLARD, 1993:184).

Desde antes de la Edad Media y hasta nuestros días se hace frecuente la pregunta por la inmortalidad. El deseo de conocer qué sucederá más allá de la muerte, en un futuro que nos ubicaría, por decirlo de alguna manera, más allá del tiempo y de las coordenadas propias de nuestra condición.

A lo largo de toda la historia de la filosofía se ha debatido la condición del tiempo. Algunos de los autores han dado preferencia al presente 42 , otros al futuro 43 y otros al pasado 44 . Para todos ellos el tiempo es real y es concebido como tal de una forma u otra. El tiempo es una parte esencial de la realidad humana o de la estructura del mundo en el que vivimos. Es pues, algo inevitable para concebir al hombre dentro de su situación o circunstancia. No es un tiempo cronológico, en sentido vulgar, del que muchos de estos pensadoras hablan, sino que es un tiempo más denso, más existencial, más óntico.

Sin embargo, la concepción de tiempo actual tiene la característica esencial de instantaneidad. Se desea la inmortalidad de la especie en tiempo real, ya no en tiempo diferido, como antes, sino en el momento. Baudrillard no habla de la muerte en el antiguo tiempo real, ni del fin en ese mismo tiempo. Tanto la inmortalidad como el fin entendidos de esa manera eran pura ilusión.

El nuevo tiempo real implica hablar del fin y de la muerte en diferido, por televisión o por video juego. Nada sucede ya en tiempo real, ni tan siquiera la historia. 
Los medios de comunicación crean el auténtico tiempo real. Ellos marcan la pauta de qué existe como hecho o qué deja de interesar. Ya no interesa la importancia o la gravedad del hecho. No interesa lo que aconteció objetivamente hablando. Los medios nos hacen presenten los hechos desde su ángulo y los mantienen vivos el tiempo que es de su interés. De esta manera nos liberamos del paso del tiempo y soñamos con superar el fin, que nunca

San Agustín sería un muy buen representante de la importancia del presente. Uno de los lugares más claros en toda su obra es el libro XI de sus Confesiones. véase además ALICI, 1994:5-19; SEOANE PINILLA, 1992:363-369; ALESANCO REINARES, 2004:303-320.

43 Heidegger sería un caso apropiado de esta opinión. Véase HEIDEGGER, 2003; GAOS,

1996:79-96; RICOEUR, 2003:463-484. En su muestra más exagerada tendríamos que mencionar los planteamientos apocalípticos de fin de milenio o de los intérpretes inspirados de los últimos signos de los tiempos.

No falta quien, hasta popularmente, defienda que cualquier tiempo pasado fue mejor. En este contexto, mas de manera cultivada, se ubican las discusiones sobre términos como historicidad (Geschichtlichkeit) o de historia (Geschischte)., véase RICOEUR, 2003:484-501.

Un hecho derivado y característico de nuestro tiempo es la tendencia a "museizar" la historia, a congelar la memoria, "La celebración y la conmemoración en sí mismas no son más que la forma suave del canibalismo necrófago, la forma homeopática del asesinato con guante de seda. Ésa es la tarea de los herederos, cuyo resentimiento hacia el muerto no tiene fin. Los museos, los jubileos, los festivales, las obras completas, los más ínfimos fragmentos inéditos, todo ello da fe de que entramos en una era activa de resentimiento y de arrepentimiento", BAUDRILLARD,1993:40. llegará. Se trata del tiempo real de los acontecimientos 45 , acelerados por los instrumentos que nos los dan a conocer. En definitiva, nos ubicamos (¡nos ubican!; no se sabe quiénes) en otras coordenadas que nos permiten ilusionarnos con la superación de las anteriores.

Debido a la absurdidad de la pregunta actual por el fin, los pensadores y la sociedad han pasado a preocuparse por el origen. La ilusión del fin retrocede ante la fuerza de la ilusión por la causa. Toda la explosión genética y clónica responden a estas inquietudes ilusorias por el génesis de todo. Se mezclan, entonces, las preocupaciones por el principio y por el fin, en una dinámica envolvente, reversible y acelerada por los medios, que después veremos qué consecuencias provocan. 
Junto con el desdibujamiento de la realidad y del tiempo, también desaparecen conceptos como creencia o valor. Hasta no hace mucho los pensadores se preguntaban por la existencia o inexistencia de Dios, de la verdad, de la realidad... Actualmente estos cuestionamientos se convierten en superfluos, porque en nuestros días simplemente refractamos lo que nos presentan sin importarnos su realidad o su credibilidad. Refractamos como espejos la ilusión de lo comunicado o de la política sin importarnos si hay que creer en ellos o no, así como al espejo no le importa la imagen que refleja.

La credibilidad se centra ahora en el objeto. La creencia se fundamentaba sobre la relación entre sujeto y objeto. La credibilidad se apoya únicamente en la (co-)ordinación entre el objeto y su código. Por lo mismo la inmortalidad de la que venimos hablando no es la del sujeto, ya no es relevante. Ni por el tiempo, ni por la realidad, ni por el sujeto se pueden seguir buscando los cauces de la inmortalidad.

Es por esto, que hay que ir más allá de la inmortalidad diferida en el tiempo.

Esta es justamente, con la diferencia de tiempo, la misma línea de lo que ya Nietzsche había percibido de la ilusión de lo que los demás llaman realidad, como ya dijimos más arriba. Feuerbach afirmó lo mismo refiriéndose a la ilusión que genera al Dios hecho a imagen del hombre. La realidad está unida a la simulación para disfrazarla y hacerla vivible. El problema radica cuando se cree que esas simulaciones son la auténtica realidad.

A la desaparición de estos metarrelatos (LYOTARD, 2003:29-32), habría que añadir en el análisis de Baudrillard, la destrucción del ámbito simbólico de la

45 Entendido este término (Ereignis) de manera muy distinta a como lo entiende Heidegger. El acontecimiento de Baudrillard queda determinado por la presentación real en los medios.

nueva realidad. Los sueños, las ilusiones, los ideales, las utopías desaparecen sustituidas por la eficiencia inmediata de los códigos y su realización

"Canetti da, con la bomba atómica, un ejemplo sobrecogedor de este asesinato de la metáfora, del sueño, de la ilusión, de la utopía a través de su realización incondicional, de cualquier idea, de cualquier trascendencia a través de su ejecución material" (BAUDRILLARD, 1993:157). 
El ámbito equilibrado y simbólico de vida y muerte se borra. Esta inversión genérica y genética, origina la confusión y ésta, a su vez, el peligro de que la humanidad abandonada a sí misma produzca su propia destrucción o repetición constante.

De este nihilismo absoluto debiera surgir, según el análisis nietzscheano, el superhombre (Übermensch) (VATTIMO, 2001). Sin embargo, nuestro autor enmienda la plana, y anuncia la aparición del subhombre (Untermensch). Reina la confusión por defecto de lo humano y de lo inhumano junto con el dominio del código, de la técnica. De la riqueza metafórica de lo vivo se ancla la realidad en la metástasis de los supervivientes.

Hasta no hace mucho el concepto de inmortalidad hacía referencia a un más allá. El más acá de la actualidad convierte esa inmortalidad clásica en la cualidad banal de la supervivencia, de la inmortalidad porque ya se está muerto y no se puede volver a morir. Se es inmortal en razón del código, en razón de la técnica, que propiamente no tienen vida y generan ambiente y ser sin vida. La difusión en la ilusión entre vida y muerte ha desaparecido. Ya no hay fines, hipertelia, no hay posibilidades. Esta inmortalidad funcional se produce en un trasmundo, que es nuestro propio mundo, y que no ofrece una alternativa de mundo real, puesto que ese trasmundo deviene en nuestro auténtico mundo real.

\section{III.2. FRANKENSTEIN [OR THE MODERN PROMETHEUS]}

"El problema de Frankenstein, por ejemplo, es que no es Otro, y que está sediento de alteridad. Es el problema del racismo. Pero nuestros ordenadores también están sedientos de alteridad, son una máquinas autistas y solteras y de lo que padecen y se vengan es de una tautología feroz de su propio lenguaje" (BAUDRILLARD, 1993:165). 
El título original de la obra romántica, o como ahora se diría: gótica, de Mary W. Shelley, nos servirá para hacer un recorrido rápido por los esfuerzos que el hombre hace para llegar a tener una identidad, algo fijo y establecido, en medio de esta circunstancia cambiante en la que le toca vivir. El engendro no humano, sí con sentimientos humanos, representa al Prometeo moderno que es fabricado con el dominio de la chispa de la vida y abre la posibilidad de poder controlar la muerte. Identidad e individualidad serán dos intenciones de Frankenstein, así como dos guías que marcarán nuestro caminar por este apartado.

Heidegger consideraba dentro de su pensamiento que la calidad de "pro-yecto" es el mismo ser del Da-sein.

"Ser nuestras posibilidades, ser posibilidad, es ser arrojándonos hacia delante, es ser „proyectándonos". Por eso el „comprender", que es el ser lo que podemos ser, el ser posibilidad, es „proyección". Ésta es el movimiento, la relación misma esencial a nuestras posibilidades, a la posibilidad que somos más radicalmente que nada, no un hacernos un "plan de vida", una representación "teórica" de nuestras posibilidades" (GAOS, 1996:47).

El "ser-ahi" está arrojado ("yecto") en el mundo para conquistar el máximo desarrollo de las potencialidades que posee. Justo, como decíamos más arriba, en la perfección o cumplimiento o límite de todas estas posibilidades consiste la inmortalidad actual. Es un contrasentido absoluto ya que se trata de una inmortalidad que implica la suma y repetición de uno mismo. Ya no es lineal ni postemporal, sino el mismo (re- o in-) volver sobre lo mismo.

"Nous ne sommes plus dans un temps linéaire, nous sommes peut-être dans un temps un peu chaotique, où il y a des récurrences, des turbulences..." (BAUDRILLARD, 1993-1994:3).

No hay propiamente fin, ni avance. Así es la caracterización de nuestro tiempo, es la oferta de realización máxima del ser humano como programa. La causa última de este fenómeno es la rapidez y la inercia propia en el desarrollo de estas posibilidades.

"Se alcanza con ello la inmortalidad de hecho, por mero olvido de la fórmula para detenerse. Inmortalidad horizontal, por aceleración y por inercia, por agotamiento de las posibilidades, y donde ya no interviene el corte vertical de la muerte. 
Más ilusoria aún que las formas trascendentes de la inmortalidad, puesto que evidencia todas las muestras de le eficacia material", (BAUDRILLARD, 1993:154).

Solamente el ámbito del lenguaje parece liberarse de este torbellino de rapidez. No hay manera, de momento, de poder explicar y dominar todos los sentidos y contenidos que se incluyen dentro de las palabras en sus diferentes contextos. Aunque a subsanar este límite es a lo que tiende en nuestros días el lenguaje informático, a utilizar todas las significaciones simultáneas y rellenar este vacío.

Esta ilusión de llegar al cumplimiento de todas las posibilidades de uno mismo es una fantasía de muerte, es la política de quienes tienen pocos recursos y están obligados a explotarlos al máximo. Viéndolo desde uno mismo favorece y necesita una cultura de autoesclavitud que opaca la presencia del otro, puesto que cada quien sustituye al otro en el papel de opresor.

Es el colmo de la esclavitud voluntaria. Nada importa, sino la autoconsumación de uno mismo. El hombre está encadenado a sí mismo por la invitación a ser él mismo. Es la figura del nuevo Prometeo encadenado por el real horizonte de los acontecimientos más allá del cual nada sucede.

Dos aspectos fundamentales existen en el "frenesí de cumplimiento": el paso a lo universal y el individualismo.

1. La universalidad es en cierto modo el equivalente a la inmortalidad en el tiempo, pero referida a la extensión. La amplitud implica un debilitamiento y una más temprana caducidad. Esto sucede con los acontecimientos, con los datos, con los conocimientos, con la información. Es el principio rápido y fugaz de su pronto acabamiento. En el cumplimiento de la extensión total se incluye su contrario: la concentración mínima hasta su desaparición total ${ }^{46}$.

2. Con la palabra individualismo no hacemos referencia al sentido burgués. Ésta es una ilusión terminada. El individualismo al que aquí se refiere habla de la apropiación técnica del yo47. Implica la 
Al igual que con los conceptos libertad, liberación y liberación Baudrillard hace también la distinción graduada entre lo local, universal y global. La universalidad se refiere a los valores de la cultura occidental; la globalización hace referencia a la tecnología y mercado. La universalidad tiende a desaparecer y la globalización llegó para quedarse. La universalidad originada desde el lluminismo, tiende hacia su muerte por crecimiento ilimitado. La globalización fue en primer momento de mercado y después de promiscuidad de signos y valores hasta llegar al concepto de "pornografía". Véase BAUDRILLARD, 2003. En otras referencias distingue entre universal y lo mundial. Éste en el mismo sentido que globalización, BAUDRILLARD, 1998:23-27. en la página 25 aparece la definición de pornografía.

47 No llega tan lejos la concepción de individualismo que presenta Lipovetsky. Sí considera la influencia y dependencia de los medios en la sociedad. Sí tiene en cuenta el reinado

claudicación y superación del yo subjetivo, o alienado o autoposeído. A esta palabra, Baudrillard la compara con la religión. Sus propiedades serían: deseos de prestaciones y de eficacia; y sus consecuencias: estrés y sumisión a la esclavitud temporal. Estas notas definitorias, curiosamente, convocan a las fuerzas más irreligiosas para constituir la "religión" más esclavizante que nunca haya existido. Es la religión sumisa y obediente a las divinidades de la información. Este individualismo ha surgido de la liberalización de las redes y de los circuitos esclavizados. Cada uno es una microred 0 un microcircuito o su propio microuniverso.

Liberalización no es, para Baudrillard, lo mismo que libertad y liberación.

1. Libertad se da dentro del espacio simbólico del sujeto, en donde se encuentra con su propio fin. Es una forma crítica que enfrenta al individuo con la alineación y con su propia superación.

2. Liberación se ejerce en un espacio en el cual se lleva las potencialidades del individuo a sus límites y más allá. Es un procedimiento casi físico. Es una forma potencialmente catastrófica que conduce a la reacción de los elementos en cadena, a la desconexión de todos ellos y a la expropiación original del sujeto.

Entre ambas, la solución es imposible. A nuestro tiempo se ha llegado mediante la superación de la libertad por medio de la liberación y de ésta mediante la liberalización. La resolución que el sistema actual ha encontrado a este enfrentamiento irresoluble es la liberalización de los intercambios. Esta es la solución final que realmente no es final.

Siguiendo con la línea del individualismo, tenemos que anunciar como mensajeros de noticias de última hora, la caída del concepto de alineación, de diferencia, de otreidad contrastante. El sujeto se inscribe en la identidad que surge paradójicamente de la necesidad de ser distinto a los demás. 
Nos oponemos a la alineación mediante la indiferencia.

absoluto del individuo y su relación con la masificación en el individuo zapeador. Sí analiza el debilitamiento de los referentes universales. Sí diviniza ("voz de Dios") la influencia de los medios y de las modas. Pero todo ello va a servir para rescatar algo de todos estos aspectos que conforme la sociedad actual postmoderna. Véase LIPOVETSKY, 2003:99-128.

"Pero los propios valores se degradan para acabar por confundirse, en el seno de un universo fractal, aleatorio y estadístico, en la diferencia y en la equivalencia, de acuerdo con una aceleración perpetua semejante al movimiento browniano de las moléculas. Así perdimos el valor de uso, seguido del buen y tradicional valor de cambio, volatizado por la especulación, y estamos a punto de perder incluso el valorsigno a favor de una señalización indefinida, de perder cualquier lógica diferencial del signo a favor de perder cualquier lógica indiferenciada... cualquier valor está situado bajo el digno de la entropía, y, de igual manera, cualquier diferencia bajo el signo de la indiferencia" (BAUDRILLARD, 1998: 13).

Hay diversos tipos de indiferenciaciones. Algunos son los siguientes:

1. Indiferencia hacia sí mismo: el individuo no difiere ya de sí mismo, por lo tanto es indiferente.

2. Indiferencia del tiempo: el tiempo real se convierte en instantaneidad y por tanto en hastío.

3. Indiferencia del espacio: contigüidad de todos los puntos del espacio

(mando a distancia) que permite no uno no esté en ninguna parte.

4. Indiferencia política: sobreabundancia de opiniones flotantes en el espacio mediático.

5. Indiferencia sexual: indistinción y sustitución de los sexos.

La diferencia ha muerto ante la lógica de lo mismo. La alteridad perece a causa de la alineación, entendida como la conversión del sujeto en el otro de sí mismo. 
Y la alineación pasa por mor de la lógica identitaria, ya que el sujeto se convierte en el mismo que él mismo.

¿Ser o no ser yo? ¿Cómo ser sin ser yo? o ¿cómo no ser yo siendo yo? ¿Soy yo a través del otro? o ¿mediante el otro que soy yo, llego a ser yo mismo? ¿La diferencia me ayuda a ser yo o refuerza realmente $\mathrm{mi}$ indiferencia? Éstas son las cuestiones. Algunas de las cuestiones que pasaban por la mente del joven Frankenstein, que buscaba saber quién era y con quién podría relacionarse. Identidad e individualidad frente a los otros, comenzando por su

propio creador, son los cuestionamientos que la también nueva sociedad prometéica y mediatizada por los medios, pone sobre la mesa.

\section{III.3. ¿... TODO DEBE CONTINUAR [SHOW MUST GO ON]?}

"Ni lo uno ni lo otro. En ese capítulo que titulé "patafísica del año 2000", partía de la idea de que ya no encontraremos la historia de antes de la información y de los medios de comunicación, de que el exceso de historia o el exceso de acontecimientos anulaba la posibilidad misma de la acción histórica. No es que los acontecimientos sean más numerosos, es que el acontecimiento en sí mismo se ha multiplicado por su difusión, por la información. Diría que como todo se ha vuelto historia ya no es posible creer en ella. Todo ha sido historizado: las mentalidades, la vida cotidiana, la sexualidad. Así que, más por exceso que por concentración, se ha perdido poco a poco el concepto y el sentido de la historia. No es el fin de la historia en el sentido de Fukuyama, por resolución de todas las contradicciones que había planteado, sino la disolución de la historia como acontecimiento: su puesta en escena mediática, su exceso de visibilidad. La continuidad del tiempo, que es una manera de definir la historia (para que exista recurrencia posible de una secuencia de sentido es preciso que exista un pasado, un presente, un futuro, con una continuidad entre ellos), está cada vez menos asegurada.

Con la instantaneidad de la información, ya no queda tiempo para la historia. En cierto modo no tiene tiempo de existir. Está cortocircuitada. Indicar este hecho no es no creer en nada, como usted dice, sino tomar nota de esta retrocurva de la historia e intentar desbaratar sus mortales efectos" (BAUDRILLARD, 1998:17-18) 48 .

Baudrillard, siguiendo un texto de Elías Canetti, hace mención del desvanecimiento de la historia (BAUDRILLARD, 1994:4). 
Éste pudiera explicarse mediante tres teorías (BAUDRILLARD, 1993:9-22):

1. Por aceleración. Se utiliza el ejemplo de la gravitación planetaria. La velocidad descontrolada de los acontecimientos y de los cambios han provocado que la humanidad se salga de la historia. La fuerza centrífuga de la simultaneidad e instantaneidad da origen a lo que denomina velocidad de liberación. El efecto final es que nos sorprendemos ubicados fuera de la esfera referencial espaciotemporal, de sentido, de lo real y de la historia. Cada acontecimiento

48

Véase BAUDRILLARD, 1993:181; FUKUYAMA, 1992; FUKUYAMA, 2003; FUKUYAMA, 1990:85-96; MARDONES, 1997:7-18.

es atómico, marca su trayectoria hasta el infinito y es independiente (BAUDRILLARD, 1993-1994:3). No hay lenguaje humano, ni acontecimiento, ni sentido, ni historia que soporte este efecto. Es la descripción, en definitiva, de un apocalipsis por aceleración.

2. Disminución de la velocidad. También sigue la imagen de un efecto estudiado por la física. El tiempo se ralentiza en la superficie de un cuerpo con mayor densidad. La historia haría más lento su paso al rozarse $o$ tratarse con las mayorías silenciosas e inertes. Los acontecimientos se producen uno tras otro y se desvanecen en la indiferencia. Las masas absorven y neutralizan tanto la historia, como el deseo, como los sentidos (BAUDRILLARD, 2003:6). La trascendencia potencial que pudiera tener cualquier evento social, histórico o temporal se autosume en la inmanencia silenciosa. Es el mismo efecto que se puede observar en las agujeros negros ("true noir") La historia implotaría en el efecto centrípeto de la actualidad sin llegar a su fin y sentido. Los efectos se aceleran, pero el sentido se vuelve más lento (BAUDRILLARD, 1993-1994:4). Es la descripción de un apocalipsis negativo.

3. Efecto estereofónico. En esta ocasión la referencia es algo tan conocido, y superado ya en nuestros días, como es el sonido estereofónico en música. En la base del mismo está el anhelo por llegar a la perfección. Existe un punto en donde se alcanza la ruptura entre lo que es música y lo que ya deja de serlo. 
Este punto se denomina vanishing point y es la frontera entre lo que era real y lo que pasa a ser hiperreal, la entrada en el modelo de la simulación. No sólo en la música acontece esto, sino también en la ciencia, en la sexualidad... Este punto de desvanecimiento es ilocalizable e irreversible. De golpe volvemos a situarnos en el origen, bien sea cuestionando el inicio de los temas reales, bien sea poniéndonos en el comienzo del nuevo modelo. El terrorismo querría ser en la historia, el punto que quisiera adelantar el fin de la misma con un solo acontecimiento. Es la descripción de un apocalipsis estereofónico.

Las tres teorías hablan de un fin que no tiene lugar y que remite, al mismo tiempo, a un inicio. Todas ellas mencionan un punto concreto que sirve como clave para hablar de un tipo distinto de realidad. Describen tres tipos de apocalipsis, aunque en ninguno de los casos lo ven como realizable. Se fundamentan como analogías de otras ciencias. Las tres forman parte de un mismo resultado que se presenta en nuestros días: la ilusión del fin.

En el mismo tenor habla Baudrillard cuando explica dos versiones compuestas de la teoría del caos. La primera de ellas es la inestabilidad exponencial. La historia sería una formación sin orden que sometida a la aceleración progresiva e incontrolada produce una ruptura en los procesos clásicamente lógicos de causa-efecto y de linealidad en el tiempo. Esta aceleración aleja las causas de sus efectos, de sus fines. Crea una estructura involutiva y envolvente que aparentemeghte se acerca al fin, pero que no puede llegar a su conclusión 49 .

Por eso no se puede hablar de fin de la historia, porque la historia no es ya lineal ni causal. Los acontecimientos se convierten en individuos dramáticos $\mathrm{y}$, al mismo tiempo, insignificantes por su caducidad.

La segunda versión es la de la estabilidad exponencial. Ésta cuenta con un punto atractivo que absorve a los demás hacia sí. Ninguna de las potencialidades se desarrolla, nada se mueve, todo llega al mismo punto del que partieron. De esta manera no existiría el fin, ya que se confunde con el principio. No hay modificación, nos movemos en un eterno volver sobre sí mismo. 
Estas dos hipótesis son incompatibles, y al mismo tiempo válidas. El método de Baudrillard conjuga perfectamente ambas posibilidades, como ya hemos visto más arriba. Su sistema en sí caótico, resulta doblemente confuso al permitir en su seno el funcionamiento simultáneo de la inestabilidad y de la estabilidad 50 .

"De este modo no habría fin porque estamos en un exceso de fin: transfinito, en una superación de las finalidades: transfinalidad. Éste es el exceso que crea turbulencias sin fin, o hasta incluso una involución y una disgregación en espiral de los sistemas del tiempo y de la historia" (BAUDRILLARD 1993:169).

Nuestros sistemas actuales se agotan en sí mismos. No tienen fortaleza suficiente como para dirigirse hacia un destino, ni hacia la alteridad; ni tan

49 Es el mismo efecto que puede observarse en los radios de una rueda de bicicleta. Cuanto más rápido se pedalea, el efecto visual es más contradictorio. Cuanto más rápido aparentemente se quiere avanzar más acelerada se ve la rueda en dirección contraria.

50 Es por este motivo que está plenamente justificado el uso de la palabra re-volución o de la palabra in-volución, tanto etimológicamente como filosóficamente, véase BONETTI, 1995:9.

siquiera, hacia la fatalidad. La metástasis interior a la que exponencialmente acelerada se ven sometidos, hace que ya no puedan llegar a su fin.

Por esto somos inmortales supervivientes, porguge la existencia segunda no tiene fin ya que el fin está en el principio ${ }^{51}$.

"El hombre totalmente reducido 0 , en otra palabra, el superviviente, decía, no es algo trágico sino cómico, porque carece de destino. Por otra parte, vive con una conciencia trágica del destino. En su sistema, continúa, el superviviente constituye una especia aparte, como un tipo de animal. En su opinión todos somos supervivientes, lo cual condiciona nuestro mundo intelectual perverso y atrofiado", (KERTÉSZ, 2004:27-28).

En lo que llevas leído, lector, habrás podido encontrar expresiones que mencionen la venida del fin; otras, hacen referencia a la imposibilidad de llegar hasta este fin. Tu pregunta será: ¿en dónde estamos?

Pues según la opinión de Baudrillard estamos en un punto que no tiene retorno hacia la historia lineal y que consiste justamente en ser puramente retorno. Ya no hay fin, ya no habrá fin, la historia se ha convertido en algo interminable (the never ending history). 
El fin es una ilusión. La historia linealmente entendida va acusando sus propios conatos de rehabilitación buscando la absolución del pasado, pero sin poder disfrutar de una resolución en el futuro.

“... alla fine del ventesimo secolo, siamo impegnatissimi a tentare di recuperare tutta la storia del Novecento, di comprendere cosa ne sia stato, e regolare i conti sospesi, fare un bilancio. In effetti non ci si riesce, si cerca di resuscitare tutto ma senza suceso, poinché ormai non siamo più nel tempo storico ma in una diversa dimensione temporale...", (BAUDRILLARD, 1992:2).

Intenta encontrar el origen, el big bang genético, para no enfrentarse al más allá del fin.

El intento por escapar de la realidad virtual es una utopía. Quizá la única que todavía pervive.

51 Este premio Nobel de literatura lo aplica en un principio a los sobrevivientes de los campos de exterminio nazi. Posteriormente, es aplicable a todos.

"Mais cette illusion de la fin est è fois une perte de l"illusion et une perte de l"utopie de la fin, on est forcé de se débrouiller avec un état transfini, c"est un terme que je ne maîtrise pas, il est mathématique, instable, hyper- réel" (BAUDRILLARD, 1993-1994:2).

Cuanto más intentamos volver a la realidad clásica más nos sumergimos en la simulación desesperanzada. La tensión rusooccidental, intentó revivir la conciencia de los pueblos y la sed democrática, pero falló. La guerra del Golfo y la de Iraq hacen sus mejores esfuerzos por reabrir los espacios bélicos, pero falló. Todo cabe en el espectro virtual y acelerado de la información, de los acontecimientos, de la manipulación y también del olvido.

La formas anteriores, de todas maneras, nunca vuelven a resurgir en estado puro. Su resurrección es ella misma hiperreal. La rehabilitación de las mismas costumbres, de las mismas estructuras, jamás tendrán el mismo sentido. Soñar con la aristocracia y la monarquía como poderes fácticos posibles supone caer en el desdibujo cómico y burlesco de lo que en algunos países de la siempre vieja Europa se denomina jet set, high society o integrantes del evanescente mundo rosa. 
Son protagonistas de la ilusión de aparentar ser lo que no son, de tener lo que no tienen, de disfrutar lo que después los empuja al suicidio, de degustar fina y fingidamente lo que nunca han probado... Es el arte de vivir de la ilusión, de la hiperrealidad, del sinsentido y de la apariencia. En el fin de siglo pasado, que tanto temor causó, se malbarataron todos los elementos de la realidad. Se saldó el comunismo y el fin del comunismo. Se saldaron por poco precio las distintas ideologías occidentales. Los laboratorios industriales saldan la mercancía del genoma humano y de los pasados virus ya caducados.

El Apocalipsis esperado en el año 2000 y cada milenio, es ilusión. Nuestro Apocalipsis no es real, es virtual. No es futuro, sino que se produce aquí y ahora. La tan ansiada inmortalidad más allá de la muerte, en la otra vida, es sustituida por la inmortalidad más acá ${ }^{52}$, la de la recesión de los fines al infinito A esta ilusión del fin nos referimos, a la huelga de los acontecimientos.

52

Respecto a la clonación nuestro autor dice: "Rappresenta una modalità di questa immotalità artificiale, se si vuole, una via per passare al di là della morte, al fine di non subire più il triste destno deglo esseri viventi, vale a dire sessuati e mortali per arrivare a trovare un sostituto totale persino dell"esser morti" (BAUDRILLARD, 1999:9).

\section{FUENTES DE CONSULTA.}

- $\quad$ AA. VV. (2003), La guerra en los medios y los medios de la guerra.

Iraq 2003, Comunicación y política México:Editores.

- $\quad$ ALESANCO REINARES, T. (2004), Filosofía de San Agustín. Síntesis de su pensamiento, Madrid:Augustinus.

Confessiones.

ALICI, L. (1994), "Temporalità e memoria nelle

L"interpretazione di Paul Ricoeur", en Augustinus 39.

Destino.

ALTHUSSER, L. (1992), El porvenir es largo, Barcelona:

AMAT-PINELLA, J. (2002), K. L. Reich. Miles de españoles en los campos nazis, Barcelona: El Aleph.

ARENDT, H.-HEIDEGGER, M. (2000), Correspondencia 1925-1975 y otros documentos de los legados, Barcelona: Herder.

(25 septiembre).

ARGULLOL, R. (2004), "La isla del tesoro", en El País 
- $\quad$ BATAILLE, G. (2001), Madame Edwarda, México: Coyoacán. humains associés 6 .

BAUDRILLARD, J. (1993-1994), “Au-delà de la fin”, en Les

BAUDRILLARD,J. (1994), “Conversaciones con Jean

Baudrillard", en

Analítica.com.

- BAUDRILLARD, J. (1999), "Il virtuale ha assorbito il reale", en

Mediamente.rai.it.

Global", en

BAUDRILLARD, J. (2003), “La violencia de lo Ctheory.net (20 agosto).

Anagrama.

BAUDRILLARD, J. (2002), Contraseñas, Barcelona:

- BAUDRILLARD, J. (1984), El espejo de la producción o la ilusión crítica del materialismo histórico, México: Gedisa.

- BAUDRILLARD, J. (1998), El paroxista indiferente. Conversaciones con Philippe Petit, Barcelona: Anagrama.

lugar, Barcelona: Anagrama.

BAUDRILLARD, J. (1993), La ilusión del fin. La huelga de los acontecimientos, Barcelona: Anagrama.

BEAUCHOT, M. (2004), La semiótica. Teorías del signo y el lenguaje en la historia, México: Fondo de Cultura Económica.

- BONETTI, J. A. (1995), "Jean Baudrillard y la desaparición de la historia", en www.hemerodigital.unam.mx.

- $\quad$ CAMPS, V. (1996), Virtudes públicas, Madrid: Austral.

- CAMPS, V. (1999), Historia de la ética. 2. La ética moderna, Barcelona: Crítica.

Baudrillard",

CARRILLO DE ALBORNOZ, C. (2002), "Entrevista a J. en El cultural de El Mundo (22 de mayo).

Fichte a

COPLESTON, F. (1991), Historia de la Filosofía 7. De Nietzsche, México: Ariel.

CORTINA, A. (1993), "Modelos éticos y fundamentación de la 
ética", en Ángel GALINDO (Ed.), La pregunta por la ética. Ética religiosa en diálogo con la ética civil, Universidad Pontificia de Salamanca, Salamanca.

- CORTINA, A. (1994), Crítica y utopía. La escuela de Francfort, Madrid, Ediciones pedagógicas.

DE BEAUVOIR, S. (1997), Los mandarines, México: Hermes.

Peretti, El

DERRIDA, J. (1997), "Carta a un amigo japonés", en Cristina tiempo de una tesis: Deconstrucción e implicaciones conceptuales, Barcelona: Proyecto A.

DERRIDA, J. (1997), "La Différance" (1998a), en Márgenes de la filosofía, Cátedra, Madrid. (Edición cibernética: "Derrida en castellano").

- DERRIDA, J. (1997), “Tímpano" (1998b), en Márgenes de la filosofía, Cátedra, Madrid. (Edición cibernética: "Derrida en castellano").

Siglo

DERRIDA, J. (1997), (2000), De la Gramatología, México: XXI.

Barcelona: Anthropos.

DERRIDA, J. (1997), (1989), La escritura y la diferencia, (agosto).

ESTULIN, D. (2004), "Los amos del mundo", en Época Barcelona: Ariel.

FERRATER MORA, J. (2001), Diccionario de filosofía,

FEUERBACH, L. (1975), La esencia del cristianismo, Salamanca: Sígueme.

FLORES GARCÍA, V. (1997), El lugar que da verdad. La filosofía de la realidad histórica de Ignacio Ellacuría, Miguel Ángel PorrúaUIA, México.

demonología, Barcelona: Belacqua.

FORTEA, J. A. (2002), Daemoniacum. Tratado de

Siglo

FOUCAULT, M. (1968), Las palabras y las cosas, México:

XXI.

Paidos.

FOUCAULT, M. (1990), Tecnologías del yo, Barcelona:

FUKUYAMA, F. (1992), El fin de la historia y el último hombre, Barcelona: Planeta. 
de la

FUKUYAMA, F. (2003), El fin del hombre. Consecuencias

Revolución Biotecnológica, Barcelona: Ediciones B.

$-$

de la

FUKUYAMA, F. (1990), “¿El fin de la Historia?”, en Claves

Razón Práctica 1.

Martin

GAOS, J. (1996), Introducción a El ser y el Tiempo de Heidegger, México: Fondo de Cultura Económica.

México.

GIDE, A. (2004), Prometeo mal encadenado, Fontamara:

- GONZÁlez DE CARDEDAL, O. (2004), "Pluralismo, unidad y convivencia en Europa", en $A B C$ (22 septiembre).

deberes míos.

GONZÁLEZ FAUS, J. I. (1997), Derechos humanos, Pensamiento débil, caridad fuerte, Sal Terrae, Santander.

HABERMAS, J. (2001), Israel o Atenas. Ensayos sobre religión, teología y racionalidad, Madrid: Trotta.

HEGEL, G. W. F. (1998), "Prólogo" en Fenomenología del Espíritu, México: Fondo de Cultura Económico.

Historia, Madrid: Alianza.

HEGEL, G. W. F. (1999), Lecciones de Filosofía de la

HEIDEGGER, M. (2000), "El nihilismo europeo", en Nietzsche II, Barcelona: Destino.

Trota.

HEIDEGGER, M. (2003), El concepto de tiempo, Madrid:

$-$

natal", en

HENELDE ABEDASSIS, H. (2001), "El retorno a la tierra Isegoría 25.

siglo $X X$, Barcelona: Crítica.

España.

INNERARITY, D. (2004), La sociedad invisible, Madrid:

445.
ISLA, A. (2003), "El futuro que pasó", en La Jornada Semanal JUARISTI, J. (2005), "Masa, poder y democracia", en $A B C$ 
703.

KANT, I. (2001), “Contestación a la pregunta: ¿Qué es la ilustración?", en Isegoría 25.

KERTÉSZ, I. (2001), Kaddish por el hijo no nacido, Acantilado, Barcelona.

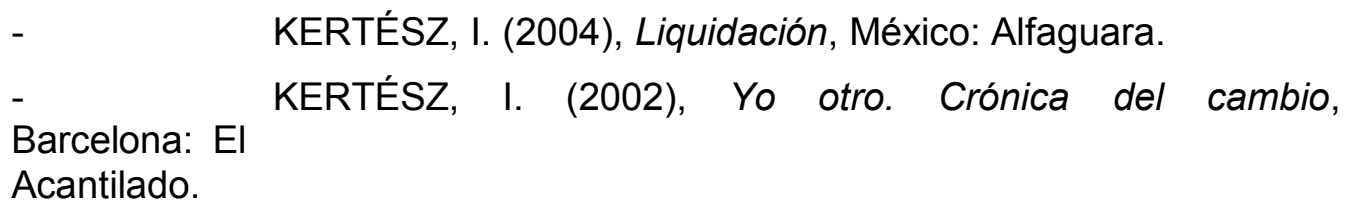

KLEMPERER, V. (2002), LTI. La lengua del Tercer Reich. Apuntes de un filólogo, Barcelona: Minúscula.

- LEÓN, F. (2003), La filosofía del vicio. La biografía definitiva del marqués de Sade, México: Nueva Imagen.

- $\quad$ LEVINAS, E. (2000), La huella del otro, México: Taurus.

- Lévi-STRAUSS, (1995), El pensamiento salvaje, cit. Por Giovanni REALE-Dario ANTISERI, Historia del pensamiento filosófico $y$ científico III. Del romanticismo hasta hoy, Barcelona: Herder.

- LIPOVETSKY, G. (2003), Metamorfosis de la cultura liberal. Ética, medios de comunicación, empresa, Barcelona: Anagrama.

- LIPOVETSKY, G. (2000), La era del vacío. Ensayos sobre el individualismo contemporáneo, Barcelona: Anagrama.

- $\quad$ LOCKE, J. (1994), Carta sobre la Tolerancia, Madrid: Tecnos.

$-$ armenio", en

LÓPEZ ALONSO, C. (2005), "La negación del genocidio El Pais (20 abril).

Berlin.

LUHMANN, N. (1990), Political Theory in the Welfare State,

- LYOTARD, J.-F. (2003), La posmodernidad (Explicada a los niños), Barcelona: Gedisa.

- MANZANO, J. (2002), Friedrich Nietzsche, México: Universidad Iberoamericana.

MARCEL, G. (1967), "La violación de la intimidad y la destrucción de los valores", en Dos discursos y un prólogo autobiográfico, Barcelona: Herder.

MARDONES, J. M. (1997), Utopía en la sociedad 
Terrae: Santander.

- PHILLIPS, R. M. (1997), "Prólogo", en Fedor. M DOSTOIEVSKI, Los hermanos Karamazov, México: Porrua.

MARÍAS, J. (1997), Historia de la filosofía, Madrid: Alianza.

MARÍAS, J. (1983), Ortega. Las trayectorias, Madrid: Alianza.

MARX, G. (2004), Groucho y yo, Barcelona: Tusquets.

1844, México: Grijalbo.

MARX, K. (1975), Manuscritos económico-filosóficos de

Global.

MCLUHAN, M.-POWERS, B. R. (1996), La aldea

Transformaciones en la vida y los medios de comunicación mundiales en el siglo XXI, Barcelona: Gedisa.

MENDIETA, M. (2001), "La lingüistificación de lo sagrado como catalizador de la modernidad" en Jürgen HABERMAS, Israel o Atenas, Madrid: Trotta.

Madrid: Trotta.

METZ, J. B. (2002), Dios y tiempo. Nueva teología política,

MORERA DE GUIJARRO, J. I. (1992), "EI estructuralismo: marginalidad del sujeto", en Moisés GONZÁLEZ GARCíA (comp.), Filosofía y cultura, Madrid: Siglo XXI. 
Revista Xihmai V (09), 81-136, Enero-junio de 2010

- $\quad$ NIETZSCHE, F. (1996a), "Sobre verdad y mentira

en

sentido

extramoral",

en

$\mathrm{F}$.

mentira, Madrid: Tecnos.

NIETZSCHE-Hans VAIHINGER, Sobre verdad $y$

NIETZSCHE-Hans

VAIHINGER

(1996b), Ecce

homo, México: Fontamara.

NIETZSCHE-Hans VAIHINGER (1997), El nacimiento de la tragedia, México: Alianza.

ORTEGA Y GASSET, J. (1981), El hombre y la gente, Revista de

Occidente en Alianza, Madrid.

- ORTEGA Y GASSET, J. (1995), La Rebelión de las masas, Barcelona: Planeta.

- PANEDAS, J. I. (1991), "El humanismo marxista", en Mayéutica

XVII.

PEÑALVER GÓMEZ, P. (2000), "Del silencio en Auschwitz a los silencios de la filosofía. Judaísmos ultramodernos interminables", en Isegoría 23.

PICÓ, J. (comp.), (2002), Modernidad y postmodernidad, Madrid: Alianza.

POPPER, K. (1999), El mundo de Parménides. Ensayos sobre la ilustración presocrática,Barcelona: Paidos Básica.

PULEO, A. H. (2003), "Moral de la transgresión, vigencia de un antiguo orden", en Isegoría 28.

- RICOEUR, P. (2003), La memoria, la historia, el olvido, Trotta: Madrid. RICOEUR, P. (1996), Sí mismo como otro, Siglo XXI:

México.

ROBERTS, D. (2002), "Marat/Sade, o el nacimiento de la postmodernidad a partir del espíritu de la vanguardia", en Joseph PICÓ (comp.), Modernidad y postmodernidad, Madrid: Alianza. 
ROBINSON, W. I. (1997), "Nueve tesis sobre nuestra época" en

Christus 698.

- ROJO, J. A. (2000), "Nietzsche, demasiado humano" en El País (20 de mayo).

Xihmai 134 
Revista Xihmai V (09), 81-136, Enero-junio de 2010

Barcelona: Tusquets.

SAFRANSKI, R. (2002), Nietzsche. Biografía de su pensamiento, - $\quad$ SAFRANSKI, R. (2003), Un maestro de Alemania. Martín Heidegger y su tiempo, Barcelona: Tusquets.

65.

SARMIENTO, S. (2004), “¿Dialogar en los medios?”, en Letras Libres

- $\quad$ SARTORI, G. (2003), Homo videns. La sociedad teledirigida, Madrid:

Taurus.

- $\quad$ SAVATER, F. (1995), Misterios Gozosos, Madrid: Espasa Calpe.

- $\quad$ SCHERPE, K. R. (2002), "Dramatización y des-dramatización de "el Fin": la conciencia apocalíptica de la modernidad y la post-modernidad", en Joseph

PICÓ (comp.), Modernidad y postmodernidad, Madrid: Alianza.

- $\quad$ TEJEDOR CAMPOMANES, C. (1993), Historia de la filosofía en su marco cultural, Madrid: Santa María.

- VATTIMO, G. (1994), "El fin de la metafísica", en César CANSINO- Víctor ALARCÓN, La filosofía Política del fin de siglo, UIA-Triana, México 1994.

- VATTIMO, G. (2001), "Supernietzsche" en La Jornada Semanal no

310.

- VATtIMO, G. (1998), El fin de la modernidad. Nihilismo y hermenéutica en la cultura posmoderna, Gedisa: Barcelona.

- V VERJAT, A.-MARTíNEZ DE MERLO, L. (2001), "Introducción”, en Charles BAUDELAIRE, Les fleurs du mal, Madrid: Cátedra.

Siglo XXI.

WALSH, W. H. (1997), Introducción a la filosofía de la historia, México:

en La Jornada.

XIRAU, R. (12-04-2004), "En un mundo tan cambiante es difícil la reflexión", - $\quad$ YEHYA, N. (2003), Guerra y propaganda. Medios masivos y el mito bélico en Estados Unidos, México: Paidos.

- ZAMORA, J. A., (2003), "Th. W. Adorno y la aniquilación del individuo", en Isegoría 28. 